Portland State University

PDXScholar

Civil and Environmental Engineering Faculty

Publications and Presentations

$5-1-2019$

\title{
Simultaneous Estimation of Ocean Tides and Underwater Topography in the Weddell Sea
}

Edward D. Zaron

Portland State University, ezaron@pdx.edu

Follow this and additional works at: https://pdxscholar.library.pdx.edu/cengin_fac

Part of the Civil and Environmental Engineering Commons

Let us know how access to this document benefits you.

Citation Details

Zaron, E. D. (2019). Simultaneous Estimation of Ocean Tides and Underwater Topography in the Weddell Sea. Journal of Geophysical Research: Oceans, 124(5), 3125-3148.

This Article is brought to you for free and open access. It has been accepted for inclusion in Civil and Environmental Engineering Faculty Publications and Presentations by an authorized administrator of PDXScholar. Please contact us if we can make this document more accessible: pdxscholar@pdx.edu. 
JGR Oceans

\section{RESEARCH ARTICLE \\ 10.1029/2019JC015037 \\ Simultaneous Estimation of Ocean Tides and Underwater Topography in the Weddell Sea}

Key Points:

- A new model for the $\mathrm{M}_{2}, \mathrm{~S}_{2}, \mathrm{~K}_{1}$, and $\mathrm{O}_{1}$ barotropic tides in the Weddell

Sea is developed from CryoSat-2 data

- The tidal dynamics are assumed to

follow a generalization of the Laplace tidal equations which uses a new parameterization of dissipation

- Variational assimilation is used to estimate tidal fields, ocean bottom topography, and water column thickness under floating ice shelves

Correspondence to:

E. D. Zaron,

ezaron@pdx.edu

Citation:

Zaron, E. D. (2019). Simultaneous estimation of ocean tides and underwater topography in the Weddell Sea. Journal of Geophysial Research: Oceans, 124, 3125-3148. https://doi. org/10.1029/2019JC015037

Received 6 FEB 2019 Accepted 14 APR 2019 Accepted article online 24 APR 2019 Published online 16 MAY 2019

(C)2019. American Geophysical Union. All Rights Reserved.

\author{
Edward D. Zaron ${ }^{1}$ (D) \\ ${ }^{1}$ Department of Civil and Environmental Engineering, Portland State University, Portland, OR, USA
}

Abstract A new model for the $\mathrm{M}_{2}, \mathrm{~S}_{2}, \mathrm{~K}_{1}$, and $\mathrm{O}_{1}$ tides in the Weddell Sea is developed by assimilating CryoSat-2 data into a barotropic tide model. A variational approach is used, which explicitly allows for errors in the water depth, that is, the bottom topography in open water and the water column thickness under floating ice shelves, so that an optimized estimate of the topography is obtained together with the tidal fields. In preparation for assimilation, the sensitivity of the tidal elevation to the interfacial drag at the sea floor and the ice-water interface (under the floating ice shelves) is investigated; this motivates the development of a new drag parameterization which is more accurate and physically plausible in comparison with the interfacial drag alone. The assimilation of CryoSat-2 data into the model results in tidal elevations with essentially the same accuracy as previous estimates, which is demonstrated by comparisons with independent in situ data and withheld CryoSat-2 data. The novelty of the present tidal estimates is that they are consistent with well-defined dynamics based on the Laplace Tidal

Equations-augmented with the new parameterization of drag — and modifications of the prior estimate of underwater topography and water column thickness. Analysis of the sensitivity to the topography finds that, at this level of precision, the topography is not uniquely determined by the observed data.

\section{Introduction}

The floating ice shelves of Antarctica play a significant role in the stability of grounded continental ice, ocean circulation and thermodynamics, and other processes related to global climate and sea level (Alley et al., 2005; Mengel et al., 2016; Orsi et al., 1999). Considerable uncertainty exists concerning the ice shelf processes affected by ocean tides, such as nonlinear processes near the grounding line, thermodynamics of freezing and melting on the underside of the shelf, and stress across the ice-water interface (Padman et al., 2018). Therefore, the mapping and dynamical modeling of tidal heights, currents, and energetics are relevant to understanding ice shelf dynamics.

Previous work has sought to determine the ice shelf tides by measurement of vertical ice motion in situ (King et al., 2011; Padman \& King, 2017) or via remote sensing by satellite altimetry (Fricker \& Padman, 2002; Padman \& Fricker, 2005; Ray, 2008; Zaron, 2018) and satellite gravimetry (Wiese et al., 2016). Another line of research has used dynamical tide models (Padman \& Kottmeier, 2000; Robertson et al., 1998; Robertson, 2005; Smithson et al., 1996), and the combination of data and dynamics via assimilation (Padman et al., 2002). The model-based studies have emphasized the importance of bottom topography and under-ice shelf geometry (which depends on both seafloor topography and the ice shelf thickness). A specific example is provided in the recent review by Padman et al. (2018), where it was shown that adjustments to RTopo-2 gridded topography (Schaffer \& Timmermann, 2016), which bring it in to better agreement with historical seismic reflection data (Johnson \& Smith, 1997; Smith \& Doake, 1994) caused up to 40-cm changes in modeled $\mathrm{M}_{2}$ amplitude, substantially improving its agreement with in situ data. Studies of coupled ocean and ice shelf dynamics have also found that tides are sensitive to ice shelf thickness (Mueller, 2014; Rosier et al., 2014).

In addition to the kinematic role of ice shelf cavity geometry, previous work has demonstrated the sensitivity of the tides to boundary layer dissipation at the sea floor and the ice-water interface. A quadratic drag law governs the frictional stress, which leads to significant nonlinearity of the tidal dynamics (Dronkers, 1964; Snyder et al., 1979; Xing \& Davies, 1995). In barotropic models the drag is usually represented by doubling the friction coefficient under the floating ice, compared to its open-ocean value, in order to account for the boundary layers at both the upper and lower water surfaces (MacAyeal, 1984); however, it is commonly 

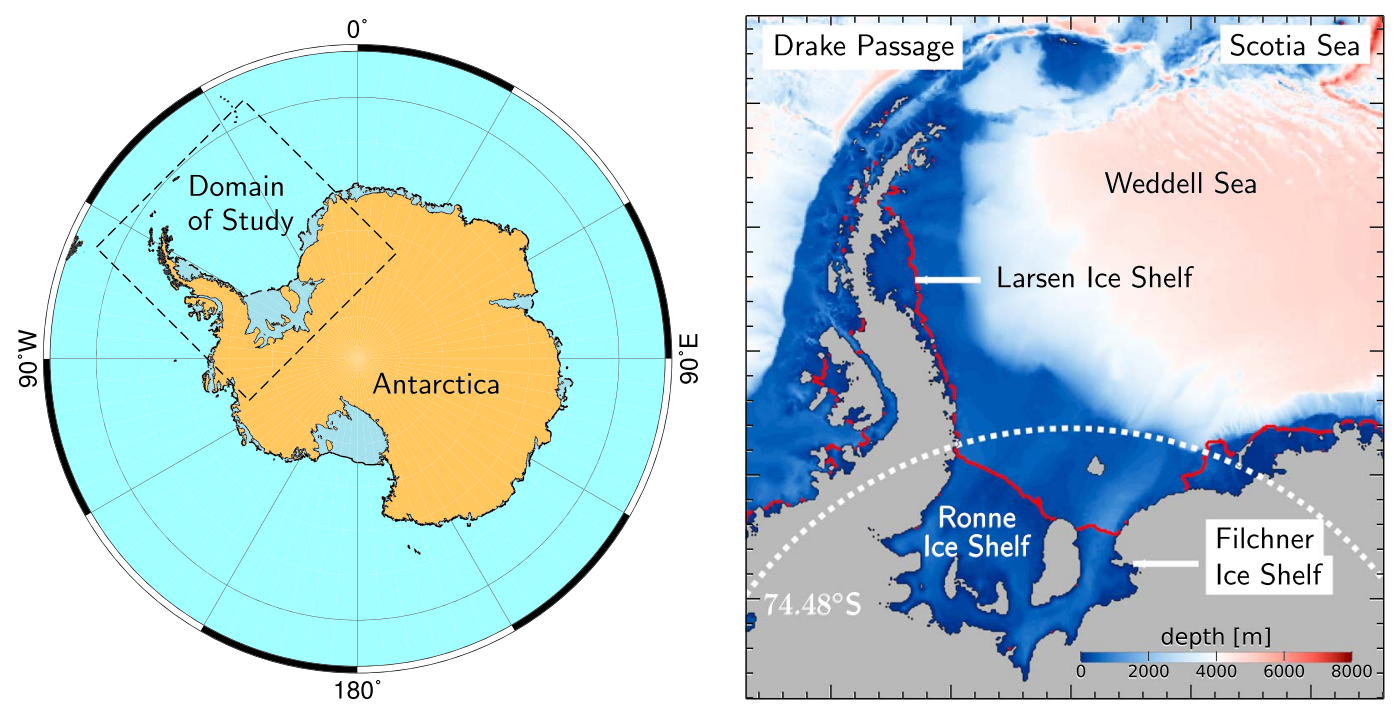

Figure 1. Domain of Study. (left) Shading indicates the land (grounded ice), floating ice shelves, and open ocean. (right) Water column thickness and ocean depth (polar stereographic projection; axis tick marks every $100 \mathrm{~km}$ ). The red line indicates the seaward edge of floating ice shelves, and the topography landward of this line is the water column thickness under the ice shelf. The dashed white line indicates the latitude of $74.48^{\circ} \mathrm{S}$, poleward of which the $\mathrm{M}_{2}$ tide is subinertial.

found that best agreement between the modeled and observed tides is obtained with unrealistically large values of the friction coefficient (Padman \& Kottmeier, 2000; Robertson et al., 1998; Rosier et al., 2014; Smithson et al., 1996). It has been hypothesized that the large friction coefficients are needed in order to make up for a range of dissipative processes which are neglected, such as inelastic flexure of the ice sheet near the grounding line, the generation of nonlinear overtides, the generation of baroclinic tides, and subgrid-scale roughness of the ice-ocean interface (Padman et al., 2002, 2018).

While the aforementioned studies discussed sensitivities to water columns thickness and drag, the data-assimilation studies have not systematically incorporated these sources of uncertainty. Instead, the model error has been incorporated as a generic body force which is adjusted to improve agreement with assimilated data (Padman et al., 2002); interpreting the body force in terms of the under-ice shelf geometry, dissipation, or other dynamics is a secondary consideration.

The present approach to modeling the tides and assimilating data explicitly acknowledges the role of uncertain and inaccurate water column thickness and uncertainty in the dissipative parameterizations. A three-stage approach is employed which uses newly available satellite altimeter data, from CryoSat-2, to estimate the tides, drag coefficients, and water column thickness. In the first stage, the dynamics of tidal dissipation are reconsidered in order to improve agreement of tidal observations with a numerical tide model. In the second stage, the adjoint sensitivity of the tide model is used to show that uncertainty in water column thickness is more influential than uncertainty in drag coefficients. Finally, in the third stage, the CryoSat-2 data are assimilated into the tide model using a variational framework which optimizes the water column thickness in relation to the altimeter data. The domain of the present work is restricted to the Weddell Sea and its adjoining ice shelves, the Larsen Ice Shelf (LIS), and the Filchner-Ronne Ice Shelf (FRIS; Figure 1).

The rest of this paper is organized as follows. Section 2 discusses data sources for gridded water column thickness, from which the tide models are derived, and the altimeter and in situ data, which are used for assimilation and validation, respectively. Section 3 provides an overview of the dynamical model and introduces new parameterizations of barotropic tidal dissipation. Section 4 uses the adjoint of the model to study the relative sensitivity of tidal elevation to water column thickness and the dissipative parameterizations. In section 5 the methodology for assimilating the large CryoSat- 2 data set is explained, which enables model-constrained estimates of tidal fields and water column thickness. Finally, section 6 applies the methodology and evaluates the results using withheld altimeter data and independent in situ data. Section 7 briefly assesses the present results in the context of other research and summarizes the main findings. 


\section{Data Sources}

\subsection{Bottom Depth and Water Column Thickness}

The bottom depth and water column thickness used in this study (Figure 1b) are taken from RTopo-2, a self-consistent compilation of gridded ice sheet topography, ice thickness, bedrock elevation, and seafloor topography (Schaffer \& Timmermann, 2016; Schaffer et al., 2016). The development of RTopo-2 utilized a complex sequence of objective and manual mapping procedures. Within the Weddell Sea and on the adjoining ice shelves, RTopo-2 is derived from the International Bathymetric Chart of the Southern Ocean (IBCSO; Arndt et al., 2013), which is largely based on the Bedmap2 seafloor and bedrock grids (Fretwell et al., 2013) and altimeter-derived maps of floating ice thickness (Griggs \& Bamber, 2011). The sea floor depths under the FRIS are based on the original Bedmap grids (Lythe et al., 2001), which were created from sounding data and unpublished data attributed to Timmermann. In deep water off the continental shelf, ocean depth is taken from the GEBCO-08 grid (Weatherall et al., 2015), a product which blends topography inferred from the altimeter-derived marine gravity field with sounding data (Marks et al., 2010; Smith \& Sandwell, 1997). On the continental shelves, the marine gravity field is not well-related to the topography (Marks \& Smith, 2012), so the gridded depth is obtained by interpolation of sparse soundings, many of which are separated by hundreds of kilometers (see Figure 1 in ; Arndt et al., 2013). Water column thickness under the ice shelves is obtained by subtracting ice thickness and bed depth from the ice surface elevation. Locations of grounding lines and ice sheet edges are determined with radar interferometry (Rignot et al., 2011) and data from the U.S. National Snow and Ice Data Center (Arndt et al., 2013).

The RTopo-2 grids comprise the initial estimate of bottom depth and water column thickness which is subsequently optimized by data assimilation. Estimates for the spatial error covariance are described later in section 5.1. Note that water column thickness is shown in Figure 1b where floating ice shelves are present, and bottom topography is shown in the open ocean. This and subsequent maps are plotted in a polar stereographic projection referenced to $70^{\circ} \mathrm{S}$ and $45^{\circ} \mathrm{W}$.

\subsection{Satellite Altimeter Data}

CryoSat-2 radar altimeter data are used here for both validation of the tide models and for assimilation. The Siral radar instrument aboard CryoSat-2 operates in different modes according to the expected surface type: SARin mode over steeply sloped ice surfaces such as ice sheet and ice shelf margins, SAR mode over ocean regions with sea ice, and LRM mode over the flat ice surfaces and the open ocean (Bouzinac, 2012). In the Weddell Sea the instrument operates in SARin mode over the floating ice shelves and the nearby ocean, and it operates in SAR mode further from shore (See Figure 2 of ; Zaron, 2018, but note that SAR mode is incorrectly referred to as LRM mode in that figure.). A data set consisting of the combined SARin and SAR mode data, processed according to Baseline-C standards, was provided by the Center for Topographic studies of the Ocean and Hydrosphere $(\mathrm{CTOH})$ for this study. Detailed information about the radar echo processing and range determination may be found in McMillan et al. $(2013,2018)$ for SARin mode and in Boy et al. (2017) and Bouffard et al. (2018) for SAR mode.

The CryoSat-2 data consist of measurements of water surface elevation and ice surface elevation along the satellite ground track at $20 \mathrm{~Hz}$. By using the satellite orbit and corrections for the tropospheric and ionospheric path delays, the range measurement is converted to a surface elevation measurement. Then, corrections for the solid Earth tide, pole tide, tidal loading, equilibrium long-period tides, dynamic atmosphere correction, and sea state bias are applied to remove nonocean tidal signals (Webb \& Hall, 2016). Note that the dynamic atmosphere correction utilizes MOG2D model predictions for the wind- and pressure-driven sea level variability over the ocean (Carrère \& Lyard, 2003) and an inverse barometer correction over the floating ice shelves. The time mean elevation has been estimated directly from the available time series, from 14 July 2010 to 21 April 2017 (orbit cycles 11 to 87), by averaging all available measurements within 3-km $\times 3-\mathrm{km}$ grid cells. Data used below were decimated from the $20-\mathrm{Hz}$ measurements by taking the median of elevation anomaly within 1-s blocks. This reduces the quantity of data handled in the tidal studies, while also averaging out small-scale nontidal variability (Zaron, 2018).

Note that other satellite altimeter data are available within the study domain. ERS-1 and ERS-2 data equatorward of $81.5^{\circ} \mathrm{S}$ were previously used in tidal studies of the Southern Ocean and Antarctica (Fricker \& Padman, 2002). These data could be used, in principle, together with data from the Envisat and Saral missions; however, the Sun-synchronous nature of these observations means they are not useful for studying $\mathrm{S}_{2}$ tides, and special retrackers must be used to obtain measurements of ice surfaces and they are not used 
here. Data from the ICEsat laser altimeter have also been used to study tides (Brenner et al., 2007; Padman et al., 2008; Ray, 2008), but the quantity of data is very small compared with CryoSat-2, so ICEsat data are not used here.

\subsection{In Situ Tide Measurements}

In situ measurements are used as independent data to evaluate tidal solutions below. The data used are a subset of the "Antarctic Tide Gauge Database" (ATGD) archive compiled by Padman and King (2017), and they consist of tidal harmonic constants for floating ice surface elevation and ocean bottom pressure. The measurement locations consist of two sites on the LIS (LAR3 and LAR1), seven sites on the FRIS (FR06, FR07, FR10, FR09, FR02, FR03, and FR05) and eight sites in the Eastern Weddell Sea (A007, A041, A042, A066, A010, A009, A002, and A008), the precise locations of which are illustrated in Figure 11 of Zaron (2018). These 17 sites were selected for their accuracy, as most are based on time series of 6 months or more of either Global Positioning System (GPS) or bottom pressure measurements (tilt-meter records were omitted). The numeric values of the harmonic constants from GPS sites with time series shorter than 6 months differ from the values found in Zaron (2018), which were taken from their original source (King et al., 2011). The reason for this difference is the use of different inference parameters to estimate the harmonic constants for the frequency pairs $\left(\mathrm{S}_{2}, \mathrm{~K}_{2}\right)$ and $\left(\mathrm{K}_{1}, \mathrm{P}_{1}\right)$ in the two data sources (Padman \& King, 2017). The difference between the values is largest for the $S_{2}$ and $K_{1}$ tides, where amplitude differences of more than $1 \mathrm{~cm}$ are noted; differences for the other tides are much smaller.

\section{Tidal Dynamics}

The development of the tide model follows previous efforts in the Southern Ocean (Padman \& Kottmeier, 2000; Robertson et al., 1998; Rosier et al., 2014), with a few innovations related to the treatment of dissipative processes, discussed below. The barotropic dynamics are expressed in terms of the horizontal volume transport vector, $\mathbf{U}$, with zonal and meridional components $(U, V)$, and the water surface elevation, $\eta$, which are functions of latitude, $\theta$, longitude, $\phi$, and time, $t$. The time-varying fields $(\mathbf{U}, \eta)$ are expanded as the sum of contributions from $k=1, \ldots, N_{c}$ astronomical tidal constituents,

$$
\begin{gathered}
\mathbf{U}(\phi, \theta, t)=\sum_{k=1}^{N_{c}} \operatorname{Re}\left[\mathbf{U}^{(k)}(\phi, \theta) \exp \left(-i \omega_{k} t\right)\right] \\
\eta(\phi, \theta, t)=\sum_{k=1}^{N_{c}} \operatorname{Re}\left[\eta^{(k)}(\phi, \theta) \exp \left(-i \omega_{k} t\right)\right],
\end{gathered}
$$

where $\left(\mathbf{U}^{(k)}, \eta^{(k)}\right)$ are complex-valued fields (harmonic constants), and $\omega_{k}$ are the frequencies of tides. In the present case, $N_{c}=4$ constituents are considered, corresponding to the $\mathrm{M}_{2}, \mathrm{~S}_{2}, \mathrm{~K}_{1}$, and $\mathrm{O}_{1}$ tides. Henceforth, the superscript indicating a particular frequency $(k)$ shall be omitted except when necessary in expressions involving more than a single frequency.

Tidal dynamics are governed approximately by the Laplace tidal equations (LTE) augmented with a linear approximation of the quadratic bottom drag law (Snyder et al., 1979) and an additional parameterization of dissipation associated with topographic vorticity waves. The augmented LTE are given by

$$
\begin{gathered}
-i \omega \mathbf{U}+f \times \mathbf{U}+g H \nabla(\eta-\Phi)+C_{d} u_{f} \frac{\mathbf{U}}{H}+\mathbf{F}=0 \\
-i \omega \eta+\nabla \cdot \mathbf{U}=0
\end{gathered}
$$

where $f=2 \Omega \sin \theta \hat{k}$ is the local vertical component of the Coriolis parameter, $\Omega$ is radian frequency of the Earth's sidereal rotation, $g=9.81 \mathrm{~m} / \mathrm{s}^{2}$ is gravitational acceleration, $H$ is the water column thickness (bottom topography in ice-free regions), $C_{d}$ is a spatially variable drag coefficient, $\Phi$ is the astronomical tide generating potential modified to include solid Earth loading and ocean self-attraction (Egbert et al., 1994), and $u_{f}$ is an estimate for the time-average near-bottom current speed. Unless otherwise stated, the drag coefficient is set to $C_{d}=C_{d}^{0}$ seaward of the ice shelves and $C_{d}=2 C_{d}^{0}$ under the ice shelves, following MacAyeal (1984), where $C_{d}^{0}$ is a dimensionless constant, $2 \times 10^{-3}$. F represents an additional dissipative term defined below. The domain, denoted $\mathcal{D}$, has boundary, $\partial \mathcal{D}$, comprising closed (material) and open boundary segments, denoted $\partial \mathcal{D}_{1}$ and $\partial \mathcal{D}_{2}$, respectively. Boundary conditions are no-normal flow on $\partial D_{1}$,

$$
(U, V) \cdot \boldsymbol{n}=0,
$$


and specified surface elevation, $\eta_{d}$, on $\partial \mathcal{D}_{2}$,

$$
\eta=\eta_{d}
$$

As already mentioned, the complex transport and elevation fields $(\mathbf{U}, \eta)$ depend on tidal frequency $(k)$, but this dependence will typically be suppressed to simplify the notation. Note that $H$ and $C_{d}$ do not depend on $(k)$.

The above model is implemented by modifying the solver described in Egbert and Erofeeva (2002). The grid resolution is approximately $6 \mathrm{~km}$ in both the $x$ and $y$ directions in the polar stereographic map projection. Tidal elevation on open boundaries, $\eta_{d}$, is taken from the TPXO9.1 tide model (Egbert \& Erofeeva, 2002, 2018). Insignificant changes were observed when the sensitivity experiments summarized in the next section were repeated using additional tides and twice-refined grid resolution; hence, the above are used in all simulations, below.

\subsection{Interfacial Drag}

The term, $C_{d} u_{f} \mathbf{U} / H$, represents the turbulent stress at the bottom of the ocean and at the top of the water column under the ice shelves. The importance of accounting for the stress under the ice shelf has been emphasized by many authors, but whether the under-ice drag coefficient should simply be doubled to account for the drag at the upper and lower surfaces (MacAyeal, 1984) or whether even larger under-ice drag coefficients are warranted is still somewhat unclear (Smithson et al., 1996) and shall be examined in detail in the next section.

Nonetheless, even the simplified form of the quadratic drag law creates a frictional coupling of the tidal frequencies through $u_{f}$, the time-average free-stream current speed. Following Snyder et al. (1979), $u_{f}$ is computed from the tidal currents, $\mathbf{U}^{(k)} / H$, and nontidal current, $u_{0}$, as

$$
u_{f}=\left(u_{0}^{2}+\gamma_{f} \frac{1}{2 H^{2}} \sum_{k}\left|\mathbf{U}^{(k)}\right|^{2}\right)^{1 / 2}
$$

The optimal value of the coefficient $\gamma_{f}$ is related to the frequency content of the tides and may be found by analysis of the quadratic bottom stress (Dronkers, 1964; Lavelle \& Mofjeld, 1983; Snyder et al., 1979). Here the values $\gamma_{f}=\sqrt{3}$ and $u_{0}=0.25 \mathrm{~m} / \mathrm{s}$ are used so that $u_{f}$ is slightly larger than the root-mean-square (RMS) current speed accounting for the resolved tides, plus a constant nontidal current. Using this approximation, the solution of (3)-(6) is iterative, with $u_{f}$ being evaluated from currents computed at the previous iteration. In practice, five iterations are typically used to produce $u_{f}$ converged to within a few percent.

\subsection{Additional Dissipation}

The last component of the dynamics to be specified is contained in the dissipative term labeled, F, above. Preliminary models developed with $\mathbf{F}=0$ were found to have larger relative errors for the diurnal tides as compared with the semidiurnal tides. It was hypothesized that the disparity in errors arises because the augmented LTEs do not adequately represent dissipative processes connected with (subinertial) topographic vorticity waves at the diurnal tidal frequencies. The rich dynamics of these waves are fundamentally controlled by the potential vorticity gradient associated with topographic slopes and can involve coupling of barotropic and baroclinic motion, as well as either surface or bottom intensification (Allen, 1975; Gratton \& LeBlond, 1986; Robertson, 2001a). Observations indicate that the waves are primarily barotropic; although, the dispersion relation is strongly influenced by mean currents and stratification (Middleton et al., 1987; Makinson et al., 2006; Skardhamar et al., 2015). Three-dimensional modeling of the Ross Sea, where similar diurnal shelf edge waves exist, found that tidal advection can lead to particle displacements across the continental slope (Padman et al., 2009), suggesting that the dynamics are nonlinear at leading order. Stratification and vertical mixing can act together, particularly near the critical latitude, to create vertical shear; although, the effective drag on the barotropic tide from these processes is unclear (Makinson, 2002).

Assuming these motions are dynamically unstable, dimensional analysis leads to two estimates for the inverse time scale of instabilities which are related to either tidal relative vorticity, $\varpi=|\nabla \times \mathbf{v}|$ or tidal advection and topographic vortex stretching, $\tau_{a}^{-1}=|\mathbf{v} \cdot \nabla H| / H$, where $\mathbf{v}$ is the RMS tidal current vector. Note that $\tau_{a}^{-1} / \omega$ may be interpreted as the Keulegan-Carpenter number, the nondimensional ratio of the 
lateral tidal displacement, $|\mathbf{v}| / \omega$, to the topographic length scale, $H /|\nabla H|$. To represent the energy loss associated with these potential instabilities, the following quasi-linear drag terms are added to the momentum equations,

$$
\mathbf{F}=C_{a} \frac{\|\mathbf{v}, \nabla H\|}{H} \mathbf{U}+C_{v} \varpi \mathbf{U}
$$

where $C_{a}$ and $C_{v}$ are nondimensional scalar coefficients for the hypothesized advective and vortical contributions to dissipation, and the norm,

$$
\|\mathbf{v}, \nabla H\|=\left(|u|^{2}\left(H_{x}\right)^{2}+|v|^{2}\left(H_{y}\right)^{2}\right)^{1 / 2}
$$

accounts for the vector nature of its arguments. Because $\mathbf{v}$ and $\varpi$ are computed from a sum over the resolved tidal frequencies, the computation of $\mathbf{F}$ involves the same iterative approach as the interfacial drag. The model for the advective contribution of $\mathbf{F}$ is similar to a parameterization of baroclinic tidal generation (Zaron \& Egbert, 2006); however, the similarity is purely formal since the latter is a linear process while $\mathbf{F}$ is intended to model nonlinear processes. For future reference, the variational derivative of $\|\mathbf{v}, \nabla H\|$ with respect to $H$, evaluated at $H=\bar{H}$ and defined with respect to any arbitrary test field, $H^{\prime}$, is given by

$$
\frac{\delta|| \mathbf{v}, \nabla H \|}{\delta H} H^{\prime}=\frac{|u|^{2} \bar{H}_{x} H_{x}^{\prime}+|v|^{2} \bar{H}_{y} H_{y}^{\prime}}{\|\mathbf{v}, \nabla \bar{H}\|}=[\mathbf{v}, \nabla \bar{H}] \cdot \Delta H^{\prime},
$$

where the latter expression provides a definition of the vector, $[\mathbf{v}, \nabla \bar{H}]$,

$$
[\mathbf{v}, \nabla \bar{H}] \equiv \frac{\left(|u|^{2} \bar{H}_{x},|v|^{2} \bar{H}_{y}\right)}{\|\mathbf{v}, \nabla \bar{H}\|} .
$$

\subsection{Calibration of the Frictional and Dissipative Parameterizations}

The augmented LTEs described above involve three coefficients, $C_{d}, C_{a}$, and $C_{v}$, related to dissipative processes. For clarity, the terms involving $C_{d}, C_{a}$, and $C_{v}$ shall be referred to as the interfacial drag, the advective drag, and the vortex drag, respectively.

The turbulent stress at the ocean bottom is commonly modeled with a quadratic drag law using an interfacial drag coefficient of about $C_{d}^{0}=2 \times 10^{-3}$. Although the value of the drag coefficient can vary as a function of roughness length, stratification, or bottom type (Hinze, 1975; Perlin et al., 2005; Yen, 1986), tide models are generally not sensitive to the value used in the deep ocean since the interfacial drag is a negligible part of the term balance there. The value of $C_{d}$ is most important near the shoreline and under the floating ice shelves.

The turbulent momentum transport across the ice/ocean interface may be modeled as the sum of contributions due to skin friction plus a contribution due to pressure drag on keels of ice that extend downward into the water column (Lu et al., 2011). Experimental determinations of $C_{d}$ for the ice/ocean interface typically find values in the range, $C_{d}=2 \times 10^{-3}$ to $8 \times 10^{-3}$, depending on how the stress is inferred (Shaw et al., 2008; Stanton et al., 2013). Recent observations beneath the McMurdo/Ross Ice Shelf indicate that the drag coefficient may be much larger, even exceeding $C_{d}=10^{-1}$ in regions with refreezing (Robinson et al., 2017). These values of $C_{d}$ are attributed to the porous and partly mobile platelet ice found on the underside of the ice sheet. The precision of these drag coefficient estimates is not known, because different measurement techniques were used during different phases of the experiment; however, the range of drag coefficients is consistent with observation in environments with similar roughness elements, so even the largest values of the drag coefficient are plausible for regions under the ice shelf, particularly where refreezing occurs (Robinson et al., 2017).

While values of $C_{d}$ well in excess of the nominal value, $2 \times 10^{-3}$, may be appropriate under the ice shelves, it is not clear where these regions of enhanced drag are located or how spatially extensive they are. The situation is further complicated by the finding that optimal agreement between tide models and tide observations requires a frequency-dependent drag coefficient (Padman et al., 2008). An example of this for the present model is shown in Figure 2, where the root-mean-square vector error (RMSVE) of the tides is shown as a function of $C_{d}^{0}$, for $C_{a}=C_{v}=0$ (solid lines). Results depend somewhat on what data set is used for comparison, the ATGD (Padman \& King, 2017) or CryoSat-2 (Zaron, 2018), but the minimum RMSVE is obtained for $C_{d}^{0}$ ranging from $6 \times 10^{-3}$ to $11 \times 10^{-3}$, depending on tidal frequency. The larger RMSVE for the ATGD is related to the proximity of these sites to the coast and ice shelves, while the smaller RMSVE for 

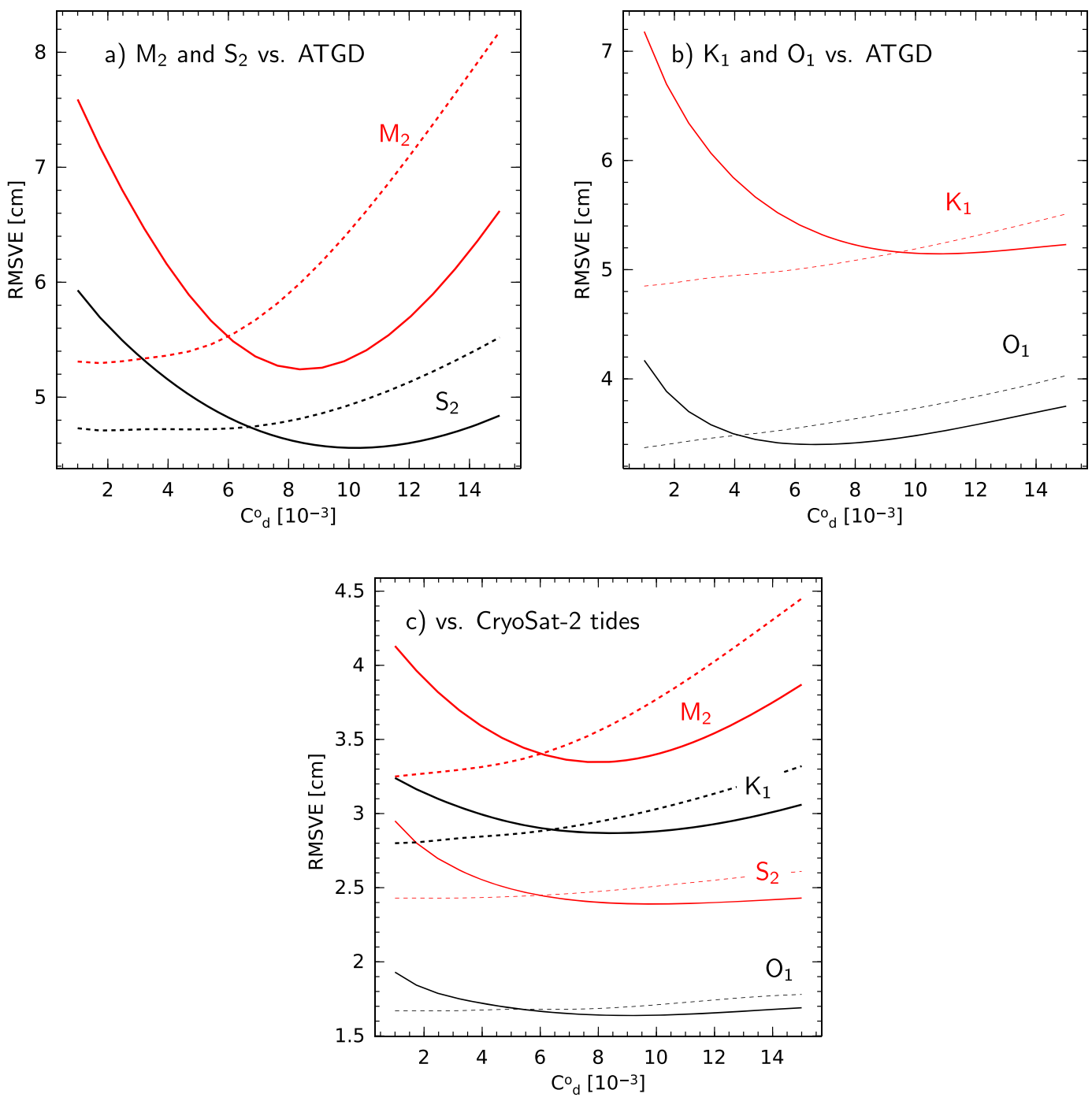

Figure 2. Root-mean-square vector error (RMSVE) of tides as a function of $C_{d}^{0}$, with $C_{a}=0, C_{v}=0$ (solid lines), and $C_{a}=0, C_{v}=2.5$ (dashed lines). Modeled tides are compared with a subset of ATGD data (Padman \& King, 2017) in panels (a) and (b). RMSVE with respect to gridded harmonic constants from CryoSat-2 (Zaron, 2018) are shown in (c). In the nominal case, $C_{a}=0, C_{v}=0$ (solid lines), the minimum RMSVE is obtained for $C_{d}^{0}$ ranging from $6 \times 10^{-3}$ (for $\mathrm{O}_{1}$ ) to $11 \times 10^{-3}$ (for $\mathrm{S}_{2}$ ). With the new drag parameterization, $C_{a}=0, C_{v}=2.5$ (dashed lines), the RMSVE is approximately optimized for $C_{d}^{0}=2 \times 10^{-3}$ for all tidal frequencies. ATGD = automated test data generation.

the CryoSat-2 data is primarily influenced by open-ocean values. The unexplained frequency dependence of optimal drag motivates the parameterizations proposed above.

To assess the possible magnitude of $\mathbf{F}$ relative to the interfacial drag, Figure 3 illustrates the inverse time scale associated with each term, nondimensionalized by $f$. The size is shown with a friction number for the interfacial drag,

$$
R_{f}=C_{d} \frac{u_{f}}{f H},
$$

an advection number for the advective drag,

$$
R_{a}=\frac{\|\mathbf{v}, \nabla H\|}{f H}
$$

and a Rossby number for the vortex drag,

$$
R_{o}=\frac{\varpi}{f}
$$



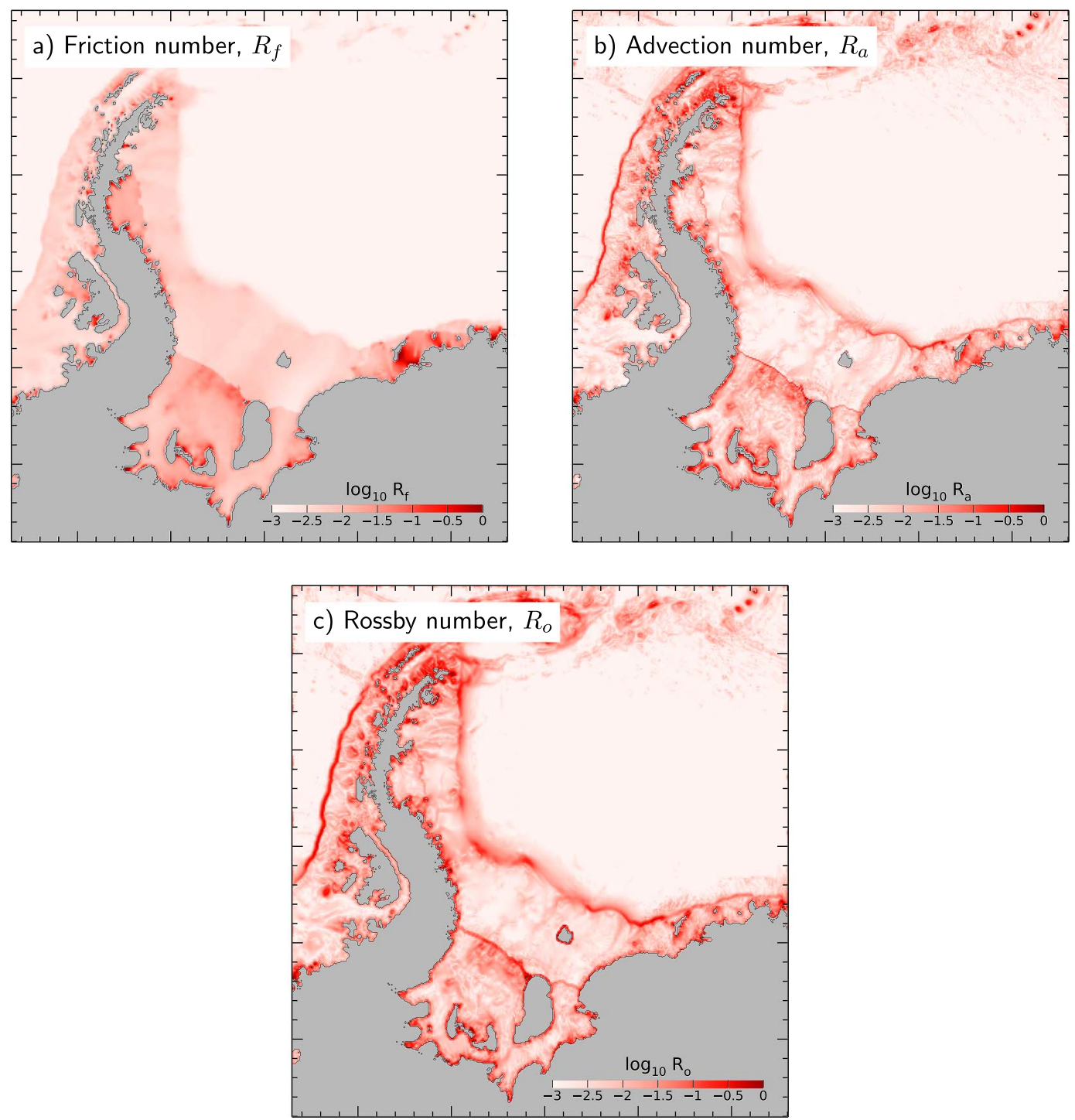

Figure 3. The inverse damping time (logarithm, nondimensionalized by $f$ ) for the (a) interfacial drag $\left(R_{f}\right),(\mathrm{b})$ advective drag $\left(R_{a}\right)$, and (c) vortex drag $\left(R_{o}\right)$ indicates that all three are of comparable magnitude.

The sizes of $R_{f}, R_{a}$, and $R_{o}$ all fall within the same range in this domain, and both the advective and vortex drag terms are large near the continental slope and the edge of the ice sheet. The small spatial scales in $R_{a}$ and $R_{o}$ result from the spatial derivatives of the topography and the velocity, respectively, which define these fields. Note that $R_{f}, R_{a}$, and $R_{o}$ are functions of the assumed tidal velocity fields, which are here computed by solving equations 3 and (4) with the nominal TPXO9.1 boundary conditions, $C_{a}=C_{v}=0$ and $C_{d}^{0}=8 \times 10^{-3}$.

More model runs were conducted in order to examine the sensitivity of tidal elevation to $C_{d}^{0}, C_{a}$, and $C_{v}$. Figure 4 illustrates the RMSVE in the $\left(C_{a}, C_{v}\right)$ plane for $C_{d}^{0}=2 \times 10^{-3}$. The dominant trend is for the error to be reduced as a function of the sum, $C_{a}+C_{v}$; however, there is a shallow minimum around the point $\left(C_{a}=0, C_{v}=2.5\right)$. The RMSVE in the figure is computed with respect to the ATGD data (Padman \& King, 2017); however, a nearly identical dependence on $\left(C_{a}, C_{v}\right)$ is found when the CryoSat-2 tidal estimates (Zaron, 2018) are used instead (not shown). The optimal $\left(C_{a}, C_{v}\right)$ is approximately $(0,2.5)$ for the $\mathrm{S}_{2}$ and $\mathrm{O}_{1}$ tides as well (not shown). With the aforementioned values $\left(C_{a}, C_{v}\right)$, the optimal value of $C_{d}^{0}$ is now close to $2 \times 10^{-3}$ for each frequency.

Taking Figures 2 and 4 together, it is apparent that a joint optimization of the drag-related parameters, $\left(u_{0}, \gamma_{f}, C_{d}^{0}, C_{a}, C_{v}\right)$, would probably further reduce the RMSVE. However, since the values of $C_{d}^{0}, u_{0}$, and $\gamma_{f}$ 

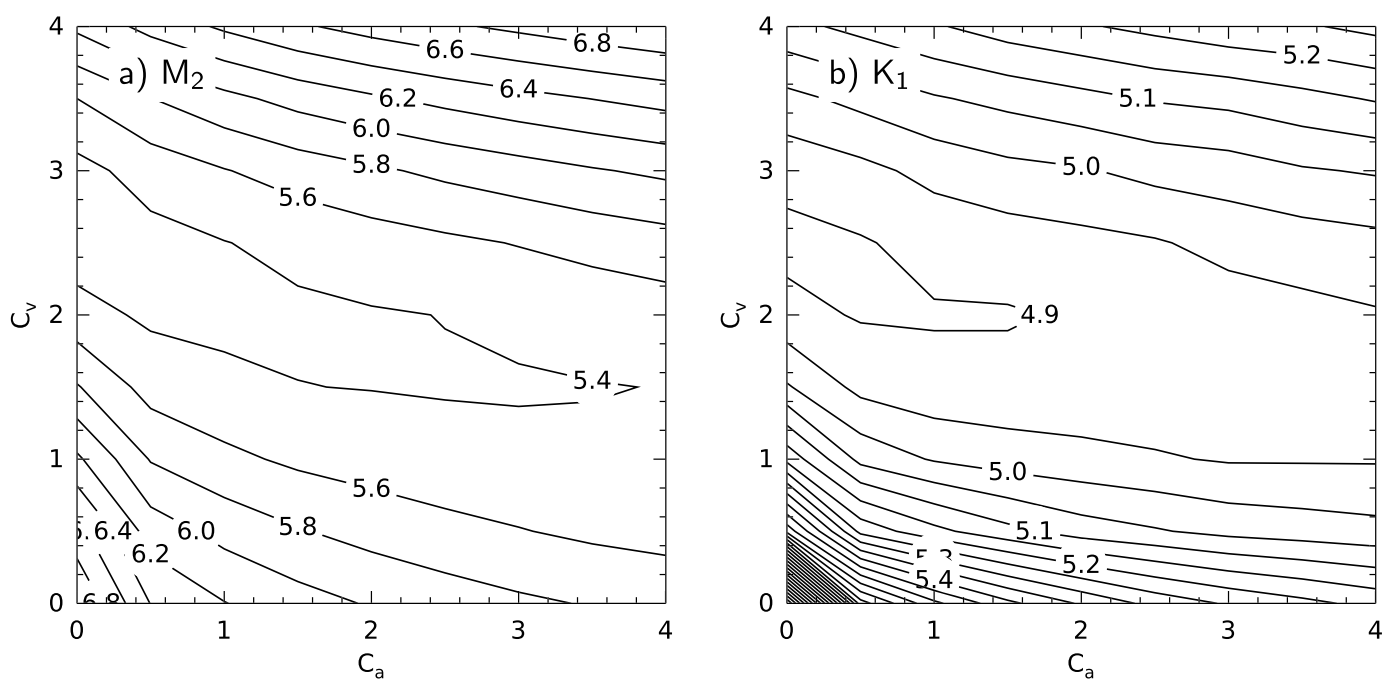

Figure 4. Root-mean-square vector error (RMSVE, units of $\mathrm{cm}$ ) for (a) $\mathrm{M}_{2}$ and (b) $\mathrm{K}_{1}$ tides as a function of the advective and vortex drag coefficients, $\left(C_{a}, C_{v}\right)$, with $C_{d}^{0}=2 \times 10^{-3}$. The RMSVE is computed relative to the ATGD (Padman \& King, 2017). Optimized values of drag coefficients are close to $C_{a}=0$ and $C_{v}=2.5$ (cf., dashed lines in Figure 2). RMSVE of the $S_{2}$ and $O_{1}$ tides is also optimized for approximately the same values of $\left(C_{a}, C_{v}\right)$ (not shown).

are physically plausible, further optimization does not seem warranted with the present data sets. Thus, the values $\left(C_{d}^{0}=2 \times 10^{-3}, C_{a}=0, C_{v}=2.5\right)$ are used henceforth.

For these chosen parameter values, the RMSVEs of the $\mathrm{M}_{2}, \mathrm{~S}_{2}, \mathrm{~K}_{1}$, and $\mathrm{O}_{1}$ tides are 5.3, 4.9, 4.7, and $3.4 \mathrm{~cm}$, respectively, compared to the ATGD. For comparison, the RMSVE of the CryoSat-2-inferred tides versus the ATGD subset is 3.0, 2.4, 2.7, and $1.9 \mathrm{~cm}$, respectively (Zaron, 2018). Since the RMSVE of the dynamical model - with the calibrated drag and dissipation parameterizations-is larger than the RMSVE of the fully empirical CryoSat-2 model, it motivates the consideration of water column thickness as a control parameter.

\section{Adjoint Sensitivity}

The previous section compared metrics of the model solutions, namely, the RMSVEs of the tidal elevations, as the values of scalar parameters were varied. This approach to examining sensitivity, while direct, is less useful when the parameters of interest are spatial fields, such as the water column thickness, $H$. Rather than specifying arbitrary perturbations of these fields and computing changes in the model outputs, it is useful to consider the "transpose" of this quantity and examine the perturbations of the field parameters associated with measurable changes in the solution. These perturbation fields are the so-called adjoint sensitivity functions, which are Green's functions for the linearized dynamics (Bennett, 1992; Errico, 1997). Equivalently, the adjoint sensitivity fields may be described as components of the Fréchet derivative of the model's dependent variables with respect to the distributed, or field, parameters (Andrews \& Hopper, 2011).

To be specific, let $\kappa_{i}^{(k)}(x, y)=\delta\left(x-x_{i}\right) \delta\left(y-y_{i}\right)$, the product of delta functions, denote the kernel which corresponds to a measurement of the complex surface elevation of the $k$ th tidal frequency at location $\left(x_{i}, y_{i}\right)$,

$$
\eta^{(k)}\left(x_{i}, y_{i}\right)=\int_{\mathcal{D}} \kappa_{i}^{(k)}(x, y) \eta^{(k)}(x, y) \mathrm{d} x \mathrm{~d} y
$$

The adjoint sensitivity which corresponds to this measurement, say, with respect to perturbations of the water column thickness, $H^{\prime}(x, y)$, is defined as the field, $\lambda_{i}^{(k)}$, such that the corresponding perturbation of $\eta^{(k)}\left(x_{i}, y_{i}\right)$ is given by

$$
\eta^{\prime(k)}\left(x_{i}, y_{i}\right)=\int_{\mathcal{D}} \lambda_{i}^{(k)}(x, y) H^{\prime}(x, y) \mathrm{d} x \mathrm{~d} y
$$

The latter expression, (16), makes it clear that one can interpret $\lambda_{i}^{(k)}(x, y)$ as a Green's function. 
Equations for the adjoint sensitivity functions may be derived from the linearization of the LTEs. For this derivation it is useful to regard $C_{d}, C_{a}$, and $C_{v}$ as spatially variable fields; although, they were treated as scalar constants above. Linearization of equations 3 and (4) proceeds with respect to a basic state solution $\left(\overline{\mathbf{U}}^{(k)}, \bar{\eta}^{(k)}, \bar{H}, \bar{C}_{d}, \bar{C}_{a}, \bar{C}_{v}\right)$, where both the dependent variables and the distributed parameters are listed explicitly. Let $\left(\mathbf{U}^{\prime(k)}, \eta^{\prime(k)}, H^{\prime}, C_{d}^{\prime}, C_{a}^{\prime}, C_{v}^{\prime}\right)$ denote a perturbation to the basic state. The tangent linearization of (3) and (4) is given by

$$
\begin{aligned}
& -i \omega \mathbf{U}^{\prime}+f \times \mathbf{U}^{\prime}+g \bar{H} \nabla \eta^{\prime}+g H^{\prime} \nabla(\bar{\eta}-\Phi) \\
& +\bar{C}_{d} u_{f} \frac{\mathbf{U}^{\prime}}{\bar{H}}+C_{d}^{\prime} u_{f} \frac{\overline{\mathbf{U}}}{\bar{H}}-\bar{C}_{d} u_{f} \frac{\overline{\mathbf{U}}}{\bar{H}^{2}} H^{\prime} \\
& +\bar{C}_{a} \frac{\|\mathbf{v}, \nabla \bar{H}\|}{\bar{H}} \mathbf{U}^{\prime}+C_{a}^{\prime} \frac{\|\mathbf{v}, \nabla \bar{H}\|}{\bar{H}} \overline{\mathbf{U}}+\bar{C}_{a} \frac{[\mathbf{v}, \nabla \bar{H}] \cdot \nabla H^{\prime}}{\bar{H}} \overline{\mathbf{U}}-\bar{C}_{a} \frac{\|\mathbf{v}, \nabla \bar{H}\|}{\bar{H}^{2}} \overline{\mathbf{U}} H^{\prime} \\
& +\bar{C}_{v} \varpi \mathbf{U}^{\prime}+C_{v}^{\prime} \varpi \overline{\mathbf{U}}=0 \quad-i \omega \eta^{\prime}+\nabla \cdot \mathbf{U}^{\prime}=0,
\end{aligned}
$$

where the superscript $(k)$ on $\mathbf{U}$ and $\eta$ has been suppressed, and where the quantities $\|\mathbf{v}, \nabla \bar{H}\|,[\mathbf{v}, \nabla \bar{H}]$, and $\varpi$, defined previously, are used. Note that an approximation to the linearization has been made, which neglects the dependence of $u_{f}, \mathbf{v}$, and $\varpi$ on the underlying tidal fields.

Let adjoint variables $(\mu, \zeta)$ correspond to dynamical variables $(\mathbf{U}, \eta)$, and let adjoint sensitivity fields $\left(\lambda, c_{d}, c_{a}, c_{v}\right)$ correspond to $\left(H, C_{d}, C_{a}, C_{v}\right)$. Equations for $\left(\mu, \zeta, \lambda, c_{d}, c_{a}, c_{v}\right)$ may be derived in a manner similar to deriving a Green's function (Zauderer, 1983); equations 17 and (18) are multiplied by the complex conjugate of $(\mu, \zeta)$, integrated over the domain, and integration by parts is used to group coefficients of $\mathbf{U}^{\prime}$, $\eta^{\prime}, H^{\prime}$, etc. What results is the so-called adjoint system,

$$
\begin{gathered}
i \omega \mu-f \times \mu-\nabla \zeta+\bar{C}_{d} u_{f} \frac{\mu}{\bar{H}}+\bar{C}_{a} \frac{\|\mathbf{v}, \nabla \bar{H}\|}{\bar{H}} \mu+\bar{C}_{v} \varpi \mu=0 \\
i \omega \zeta-\nabla \cdot(g \bar{H} \mu)=-\kappa_{i} \\
\lambda=-g \mu^{*} \cdot \nabla(\bar{\eta}-\Phi)-c_{d} \frac{\bar{C}_{d}}{\bar{H}}-c_{a} \frac{\bar{C}_{a}}{\bar{H}}+\nabla \cdot\left(\overline{C_{a}} \frac{[\mathbf{v}, \nabla \bar{H}]}{\bar{H}} \mu^{*} \cdot \overline{\mathbf{U}}\right) \\
c_{d}=-u_{f} \frac{\mu^{*} \cdot \overline{\mathbf{U}}}{\bar{H}} \\
c_{a}=-\frac{\|\mathbf{v}, \nabla \bar{H}\|}{\bar{H}} \mu^{*} \cdot \overline{\mathbf{U}} \\
c_{v}=-\varpi \mu^{*} \cdot \overline{\mathbf{U}} .
\end{gathered}
$$

Boundary conditions on $\partial \mathcal{D}_{1}$ and $\partial \mathcal{D}_{2}$ are $\zeta=0$ and $\mu \cdot n=0$, respectively.

The adjoint sensitivities depend on the basic state fields, $\left(\overline{\mathbf{U}}^{(k)}, \bar{\eta}^{(k)}, \bar{H}, \bar{C}_{d}, \bar{C}_{a}, \bar{C}_{v}\right)$, and the measurement kernel, $\kappa_{i}^{(k)}$. The interfacial friction speed, $u_{f}$, the cross-isobath flow, $\|\mathbf{v}, \nabla \bar{H}\|$, and the relative vorticity, $\varpi$, are also functions of the background fields and depend explicitly on $\left(\bar{H}, \overline{\mathbf{U}}^{(k)}\right)$.

Adjoint sensitivity fields for tidal elevation at a mid-FRIS site is shown in Figure 5. The adjoint sensitivity fields can be difficult to intercompare because the physical units of the variational derivatives, for example, $\lambda=\delta \eta / \delta H$, depend on the units of the numerator and the denominator. For the purpose of visualization, the sensitivity is plotted using units of elevation to indicate the change of $\eta^{(M 2)}$ for a unit change in the denominator. For example, the sensitivity to $H$ (Figure 5a) is illustrated with the quantity, $\lambda$ times $\bar{H}$; a $100 \%$ change in $H$ over a 6-km $\times 6-\mathrm{km}$ grid cell will result in a change in $\eta$ equal to the value shown, the maximum value of which is about $+0.4 \mathrm{~mm}$ according to the color scale. The sensitivity to $C_{d}$ (Figure $5 \mathrm{~b}$ ) is also scaled 

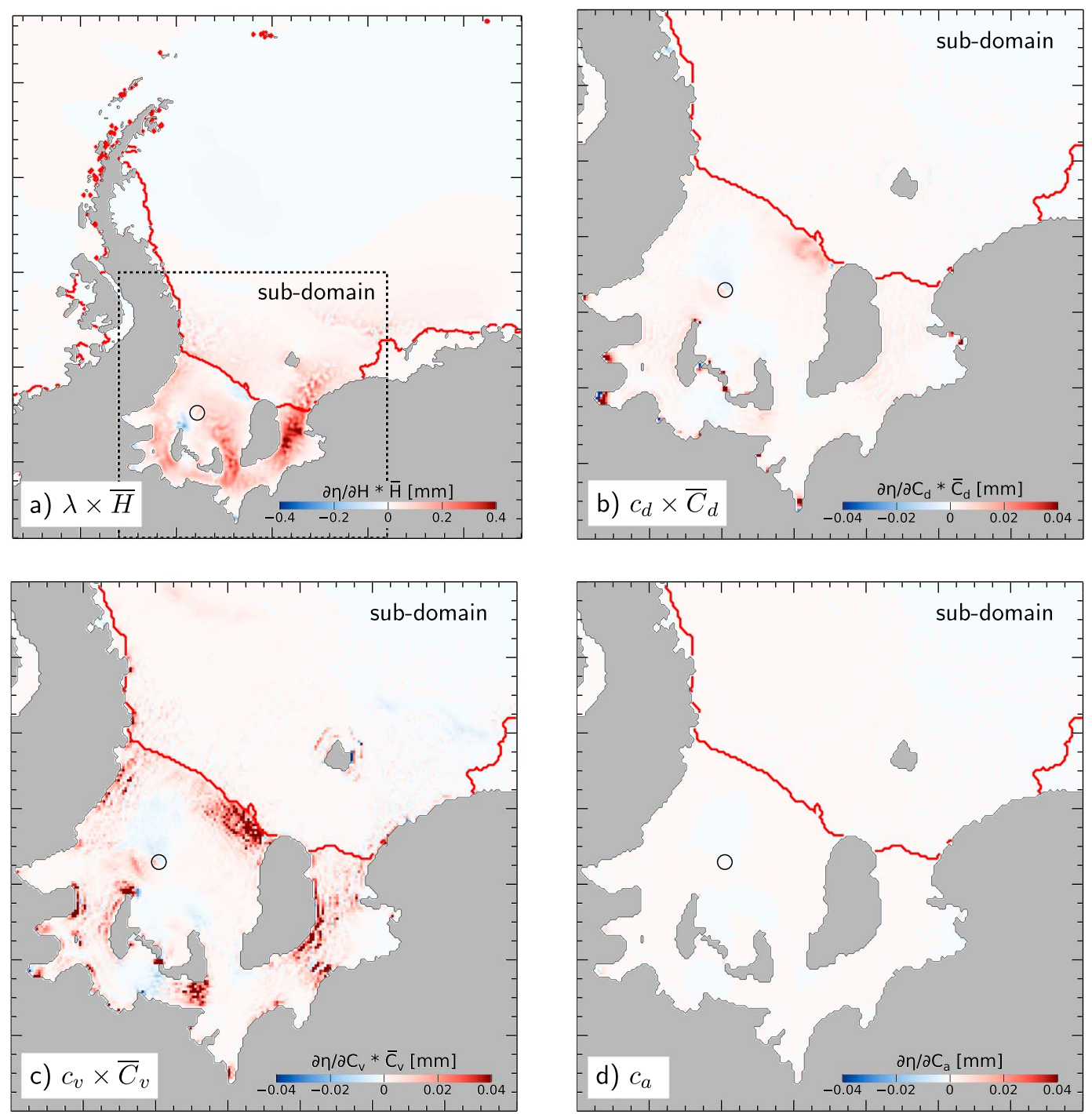

Figure 5. Adjoint sensitivity of $\operatorname{Re}\left[\eta^{(M 2)}\right]$, the in-phase component of $\mathrm{M}_{2}$ tidal elevation, at a mid-FRIS site (circled). The relative sensitivity to (a) water column thickness, $H$, is much larger than the sensitivity to (b) interfacial drag, $C_{d}$, (c) vortex drag, $C_{v}$, or (d) advective drag, $C_{a}$. Note that the color scale displayed in panels (b)-(d) is a factor of 10 smaller than the scale in panel (a). Dashed line in (a) indicates the subdomain shown in panels (b)-(d).

by $\bar{C}_{d}$ and indicates a maximum range of roughly $\pm 0.04 \mathrm{~mm}$; although, larger values of $c_{d}$ occur near the grounding lines on the western side of the FRIS. The relative sensitivity to $C_{v}$ (Figure 5c) is also largely within the same range $\pm 0.04 \mathrm{~mm}$, approximately. Since the optimized value of $C_{a}$ is $\bar{C}_{a}=0$, the sensitivity to $C_{a}$ (Figure 5d) is not scaled; regardless, it is numerically even smaller than the other sensitivities. The key observation from Figure 5 is that the sensitivity to topography is, overall, significantly larger than the sensitivities to $C_{d}, C_{v}$, or $C_{a}$.

The adjoint sensitivity of $\eta^{(M 2)}$ at other locations (not shown) shows similar patterns of sensitivity to $H$ over relatively large scales, and a lesser sensitivity to $C_{d}$ and $C_{v}$, with local maxima near the grounding line for $C_{d}$ and near the ice shelf edge for $C_{v}$. The sensitivity to $C_{d}$ near the grounding line occurs because of the $1 / \bar{H}$ dependence of $c_{d}$, equation (22), especially in the channels where tidal transport is large (Zaron, 2016, 2017). The adjoint sensitivities of the other tides show significant differences in detail (not shown), but exhibit the same relative sensitivity to $H$ compared to the dissipation parameters. For $\mathrm{K}_{1}$ and $\mathrm{O}_{1}$, the sensitivities to $H$ and $C_{v}$ exhibit overlapping spatial patterns on the continental shelf break, which indicates that it is not possible to unambiguously distinguish the influence of $H$ and $C_{v}$ on the diurnal tides. 


\section{Data Assimilation for Simultaneous Estimation of Tides and Topography}

The sensitivity of tides to topography and basin geometry is well known (e.g., Lefevre et al., 2000), and efforts to obtain accurate bathymetry for tidal modeling are ongoing (Carrère et al., 2015). The previous discussion has shown the degree to which the dissipative parameters, $C_{d}^{0}, C_{a}$, and $C_{v}$, influence the accuracy of a model for tides in the Weddell Sea, but an analysis of the adjoint sensitivities indicates that further optimization ought to be performed by adjusting $H$. In this section variational data assimilation is used to compute the topographic perturbation necessary to further improve the tide model, as measured by its agreement with CryoSat-2 observations.

The water column thickness is estimated as an approximate minimizer of the penalty function,

$$
\begin{gathered}
\mathcal{J}(H)= \\
\left(\frac{\tau}{A}\right)^{2} \int_{\mathcal{D}} \mathrm{d} x^{\prime} \mathrm{d} y^{\prime} \int_{\mathcal{D}} \mathrm{d} x \mathrm{~d} y[H(x, y)-\bar{H}(x, y)] C_{H}\left(x, y ; x^{\prime}, y^{\prime}\right)^{-1}\left[H\left(x^{\prime}, y^{\prime}\right)-\bar{H}\left(x^{\prime}, y^{\prime}\right)\right] \\
+\left(\frac{\tau}{L}\right)^{2} \sum_{k} \int_{\partial D_{2}} \mathrm{~d} s^{\prime} \int_{\partial D_{2}} \mathrm{~d} s\left[\eta^{(k)}(s)-\eta_{d}^{(k)}(s)\right] C_{O B}\left(s ; s^{\prime}\right)^{-1}\left[\eta^{(k)}\left(s^{\prime}\right)-\eta_{d}^{(k)}\left(s^{\prime}\right)\right]^{*} \\
+\sum_{i}\left[\eta\left(x_{n}, y_{n}, t_{n}\right)-d_{i}\right]^{2} / \sigma_{i}^{2}
\end{gathered}
$$

which is a maximum likelihood estimator when $H$ is a Gaussian field with known mean, $\bar{H}$, and spatial covariance function, $C_{H}$, and assuming unbiased measurements $d_{i}$, for $i=1, \ldots, N$, are given with known error variance $\sigma_{i}^{2}$. Note that $\eta\left(x_{i}, y_{i}, t_{i}\right)$ is computed from $H$ via equations 2-(4). $C_{O B}$ is the spatial covariance of tidal elevation on the open boundary, and $\eta_{d}^{(k)}$ is the open boundary data for tidal frequency $\omega_{k}$. The scalars $A$ and $L$ are the area of the domain and the length of the open boundary, respectively, making $\mathcal{J}$ dimensionless. $\tau$ is a scalar trade-off parameter used to optimize the goodness of fit (Egbert \& Erofeeva, 2002).

The data error $\sigma_{i}$ is estimated as the standard deviation of the data within $(7 \mathrm{~km})^{2}$ spatial bins. This is a spatially variable quantity with a median of roughly $0.7 \mathrm{~m}$ in the open ocean, but values larger than $5 \mathrm{~m}$ occur at the ice shelf edge and in the proximity of the coast and drifting sea ice (a map is shown in Figure 10 of ; Zaron, 2018). Because the tidal model is based on barotropic dynamics, it is not capable of representing baroclinic signals in the altimetry that are considered a type of data error. Fortunately, the baroclinic tidal elevation is at most a few centimeters (Robertson, 2001b), and it is regarded as insignificant compared to the nontidal signals. To the extent that the parameterizations of $C_{H}$ and $C_{O B}$ described below are reliable, the quantity, $\tau \sigma_{i}$, may be regarded as an improved estimate of the data uncertainty which accounts for both instrumental measurement error and nontidal signals.

\section{1. $C_{H}$, the Spatial Covariance of Water Column Thickness}

Models for the spatial statistics of the water column thickness are difficult to develop from first principles as they involve a consideration of geolocation and depth error in the original bathymetry data (Marks \& Smith, 2008; Smith, 1993) and error related to interpolation, extrapolation, and gridding (Jakobsson et al., 2002; Jakobsson et al., 2005; Marks et al., 2010; Smith, 1993). The difficulties are compounded by the inhomogeneous density and sparsity of the observations (Schaffer et al., 2016; Wessel \& Chandler, 2011).

In the development of the Bedmap2 grids, Fretwell et al. (2013) demonstrated that interpolation errors grow approximately linearly with distance from the bathymetric control points, reaching a standard error of 130 to $300 \mathrm{~m}$ beyond a distance of $20 \mathrm{~km}$. The standard error of the altimeter-derived ice thickness is about $100 \mathrm{~m}$ (Griggs \& Bamber, 2011); although, it is clearly scale dependent and may be much larger in the vicinity of narrow features (Fretwell et al., 2013). The standard error of ice sheet thickness is probably larger than that of the depth soundings under the ice, so it provides a lower bound on the uncertainty of water column thickness. A more significant problem under the ice is the uncertain bed depth under the south and west portions of the FRIS, and under the LIS. Anecdotal comments suggest that the actual depth can be hundreds of meters deeper than indicated in the gridded products in channels within the ice cavity (Padman et al., 2018). The interfaces between various data types are also likely to present larger errors, as data within buffer regions at the edges of preexisting grids are downweighted in order to smoothly join them (Arndt et al., 2013; Fretwell et al., 2013). 


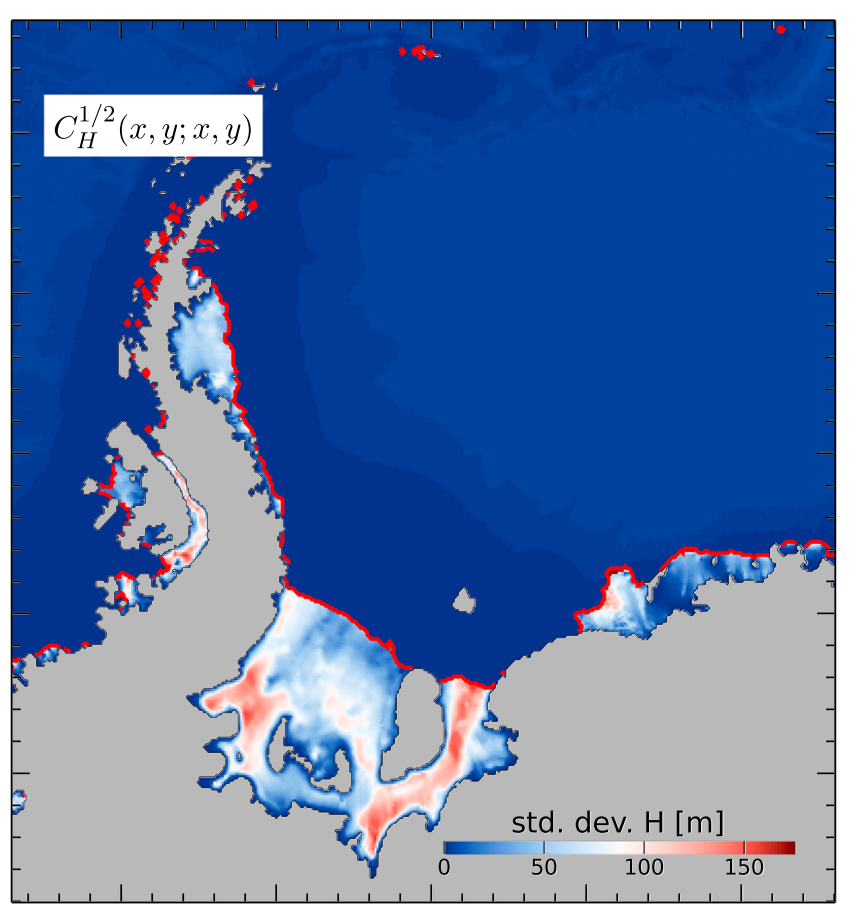

Figure 6. Spatial standard deviation of water column thickness, $C_{H}^{1 / 2}(x, y ; x, y)$, in equation (26).
The error covariance of the RTopo-2 grid, $C_{H}\left(x, y ; x^{\prime}, y^{\prime}\right)$, is represented in the following factored form based on a bell-shaped spatial correlation,

$C_{H}\left(x, y ; x^{\prime} y^{\prime}\right)=\alpha(x, y) \bar{H}(x, y) \exp \left(-\frac{\left(x-x^{\prime}\right)^{2}+\left(y-y^{\prime}\right)^{2}}{2 L^{2}\left(x, y ; x^{\prime}, y^{\prime}\right)}\right) \bar{H}\left(x^{\prime}, y^{\prime}\right) \alpha\left(x^{\prime}, y^{\prime}\right)$.

By design this function is symmetric, $C_{H}\left(x, y ; x^{\prime} y^{\prime}\right)=C_{H}\left(x^{\prime}, y^{\prime} ; x, y\right)$, and satisfies generic properties of an autocovariance function (Cressie $\&$ Wilke, 2011). The spatial standard deviation, $C_{H}^{1 / 2}(x, y ; x, y)=$ $\alpha(x, y) \bar{H}(x, y)$, is expressed as a fraction, $\alpha$, of the prior water column thickness, $\bar{H}$. It is equal to $10 \%$ under the ice shelves and $0.5 \%$ elsewhere, see Figure 6 . Note that the covariance function $C_{H}(x, y ; x, y)$ tapers to zero at the coastlines and grounding lines, which can be regarded as a physical realizability condition (Zaron, 2016).

The bell-shaped correlation function is computed from the fundamental solution of a diffusion equation where the pseudo-diffusivity is proportional to $L^{2}(x, y ; x, y)=L_{0}^{2}(x, y) \quad$ (Mirouze \& Weaver, 2012). The correlation is continuously differentiable at all orders at zero separation, which suppresses spurious spatial singularities (Bennett \& Budgell, 1987). The length scale, $L_{0}(x, y)$, is spatially variable with nominal value $L_{0}(x, y)=$ $100 \mathrm{~km}$ under the ice shelf, and $L_{0}(x, y)=200 \mathrm{~km}$ elsewhere; however, these values are modified to accommodate several considerations. First, the error is assumed uncorrelated between locations $(x, y)$ and $\left(x^{\prime}, y^{\prime}\right)$ across the ice shelf front; this is implemented with zero pseudo-diffusivity at the ice shelf front. Second, the nominal correlation scale is clipped to a maximum value related to a topographic length scale, $L_{0}<\bar{H} /|\nabla \bar{H}|$. This condition is important as it links the physical scale of the topographic gradients, $\bar{H} /|\nabla \bar{H}|$, with the scale of permissible perturbations. Without this limiter, cross-gradient correlations lead to unrealistic topographic estimates.

\section{2. $C_{\mathrm{OB}}$, the Spatial Covariance of Open Boundary Conditions}

The spatial covariance of the open boundary condition error is represented as a spatial autoregressive function with a correlation length of $250 \mathrm{~km}$. Experiments (not shown) indicated that the minimizer of $\mathcal{J}$ is insensitive to the choice of this correlation length. The boundary condition variance, $C_{\mathrm{OB}}(s, s)$, is chosen as $2.5 \%$ of the squared amplitude of the prescribed complex-valued data, $\eta_{d}^{(k)}$, from the TPXO9.1 global tide model. This value was chosen based on experience with previous TPXO models (Zaron \& Egbert, 2006; Stammer et al., 2014). Experiments (not shown) indicate that incorporating an open-boundary error of this magnitude improves agreement with independent (not assimilated) ATGD data by about $0.5 \mathrm{~cm}$ in RMS (see

Table 1

Summary Comparison Tide Models Versus the Subset of the ATGD (Padman \& King, 2017) Used in Zaron (2018)

\begin{tabular}{|c|c|c|c|c|c|}
\hline \multicolumn{6}{|c|}{ Root-mean-square vector error $(\mathrm{cm})$} \\
\hline & & & \multicolumn{3}{|c|}{ CryoSat-2-based models } \\
\hline & TPXO9.1 & Prior model & $\begin{array}{l}\text { Nominal } \\
(\tau=0.1)\end{array}$ & $\begin{array}{c}\text { Underfit } \\
(\tau=700)\end{array}$ & $\begin{array}{c}\text { Zaron (2018) } \\
\text { (IRWLS) }\end{array}$ \\
\hline $\mathrm{M}_{2}$ & 11. & 5.3 & 3.7 & 3.5 & 3.0 \\
\hline $\mathrm{S}_{2}$ & 7.7 & 4.7 & 3.1 & 2.4 & 2.4 \\
\hline $\mathrm{K}_{1}$ & 3.3 & 4.9 & 3.3 & 3.4 & 2.7 \\
\hline $\mathrm{O}_{1}$ & 3.7 & 3.4 & 2.3 & 2.5 & 1.9 \\
\hline
\end{tabular}

Note. ATGD = Antarctic Tide Gauge Database; IRWLS = iteratively reweighted least squares. 
Table 1 in section 6, below). The impact of $H$ adjustments is larger than the impact of the boundary condition adjustments.

\subsection{Approximate Optimization Over a Reduced Basis of Representer Functions}

In principle, each observation, $d_{n}$, constrains a one-dimensional subspace of $H$ spanned by a so-called representer function related to the adjoint sensitivity shown in Figure 5a (Bennett, 2002). In the present case there are $N=2,014,634$ measurements provided by CryoSat-2, which densely cover the entire computational domain (Zaron, 2018). The approximate minimizer of $\mathcal{J}(H), H=\hat{H}$, is computed by expanding $\hat{H}$ as the sum of $\bar{H}$ and a linear combination of representer fields and minimizing $\mathcal{J}$ as a function of the expansion coefficients. In practice, the size of $N$ makes this approach impractical, and instead, the set of representer functions is truncated at some number $N^{\prime}<N$ and $\mathcal{J}$ is optimized over this smaller set of coefficients; this is the reduced-basis approach described in Egbert and Erofeeva (2002). Specification of $N^{\prime}$ is analogous to the choice of "spline knots" in the theory of smoothing splines(Wahba, 1990).

The representer functions are computed from the tangent linear model, equations 17-(18), forced by topographic perturbations, $H_{i}^{\prime}$, equal to the integral of the spatial error covariance times the adjoint sensitivity,

$$
H_{i}^{\prime}(x, y)=\int_{D} C_{H}\left(x, y ; x^{\prime}, y^{\prime}\right) \lambda_{i}\left(x^{\prime}, y^{\prime}\right) \mathrm{d} x^{\prime} \mathrm{d} y^{\prime},
$$

where $\lambda_{i}$ is obtained by solving equations 19-(24).

The representer functions, $\eta^{\prime}(\mathrm{k})$, quantify the extent to which the water level measurements at each site influence the tidal estimates in the entire domain, accounting for uncertain water column thickness. Examples of these fields are presented in Figure 7 for three measurement sites (circled) located on the Ronne (Figures 7a and $7 \mathrm{~b}$ ), Filchner (Figures 7c and 7d), and Larson (Figures 7e and 7f) ice shelves. Thus, measurements at the mid-Ronne site are primarily correlated with $\mathrm{M}_{2}$ tides to the west of that site (Figure 7a) and correlated with $\mathrm{K}_{1}$ under the Filchner Ice Shelf on the opposite side of Berkner Island (Figure 7b). Measurements at the Filchner Ice Shelf are strongly related to $\mathrm{M}_{2}$ along the nearby coast (Figure $7 \mathrm{c}$ ) and $\mathrm{K}_{1}$ along the western grounding line of the Ronne Ice Shelf (Figure 7d). LIS water level observations are related to tides at the nearby grounding line and also further south (Figures $7 \mathrm{e}$ and $\mathrm{f}$ ).

Note that the square root of the magnitude of the $\eta_{i}$ representer functions ranges from 1 to several centimeters, which is of the same magnitude as the model-data misfit (cf., Figure 2). This suggests that the magnitude and correlation scales prescribed for the water column thickness, as encoded in $C_{H}$, are plausible. The contribution from $C_{\mathrm{OB}}$ are of smaller magnitude and exhibit different spatial structure (not shown).

The spatial structure of the local regression used in Zaron (2018) was motivated purely by the temporal sampling characteristics of the CryoSat- 2 orbit. One of the advantages of the data-assimilative approach is that the dynamics instead provides the spatial structure of the tidal fields, as partly illustrated by Figure 7.

\section{Results}

As mentioned above, even after decimating the CryoSat-2 data within the domain to obtain 1-Hz along-track averages (Zaron, 2018), there are still about two million observations. In order to choose a subset of $N^{\prime}<N$ basis functions distributed over the computational domain, the orbit cross-over locations of CryoSat- 2 were sorted according to nearest-neighbor distance modified to account for the barotropic wave speed, $(g \bar{H})^{1 / 2}$, as follows:

$$
d^{2}\left(x_{i}, y_{i} ; x_{j}, y_{j}\right)=\left[\left(x_{i}-x_{j}\right)^{2}+\left(y_{i}-y_{j}\right)^{2}\right]\left[\left(g \bar{H}\left(x_{i}, y_{i}\right)\right)^{-1}+\left(g \bar{H}\left(x_{j}, y_{j}\right)\right)^{-1}\right]
$$

A plot of mean separation versus number of cross-over sites, Figure 8, shows that 500 sites cover the domain with a mean nearest-neighbor separation of about $70 \mathrm{~km}$, somewhat smaller than the nominal topographic correlation scale, $L_{0}$. With the crossover sites sorted, it is straightforward to refine the reduced basis as $N^{\prime}$ is increased. The location of the first 500 sites is shown in Figure 9. 

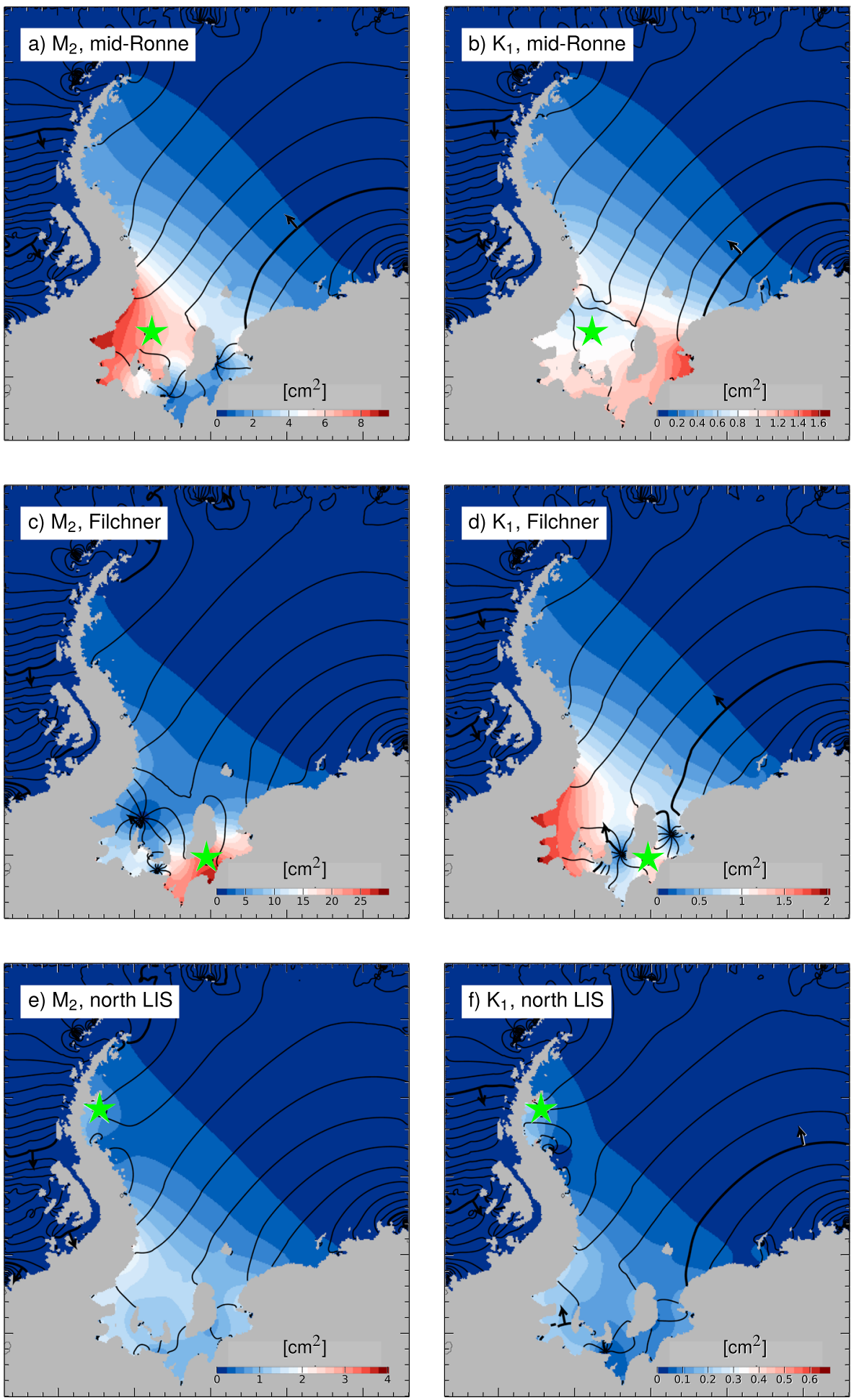

Figure 7. Representer functions $\eta_{i}^{(k)}$, which are the cross covariance between the complex-valued $\eta^{(k)}(x, y)$ field and $\eta^{(k)}\left(x_{i}, y_{i}\right)$ at the site indicated (green star). The complex amplitude and phase of $\eta_{i}^{(k)}$ are indicated as in a cotidal plot. 


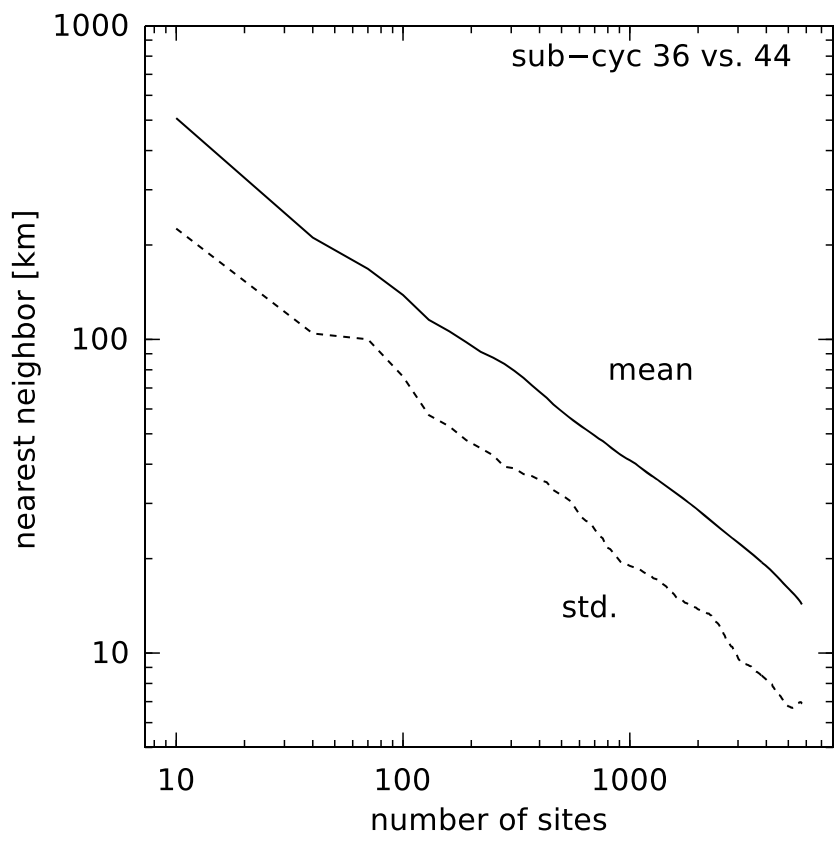

Figure 8. Distribution of CryoSat-2 crossover nearest-neighbor distances. Nearest-neighbor distance is used to select subsets of points for computing the reduced basis of representer functions. The mean spacing of the 500 sites selected for the reduced basis is approximately $70 \mathrm{~km}$ (solid line). The standard deviation of separation (dashed line) varies smoothly as a function of scale.

The estimator for $H$ is sensitive to the prescribed spatial covariance model, $C_{H}$, the first guess, $\bar{H}$, data error, $\sigma_{i}$, and the size of the reduced basis, $N^{\prime}$. To develop an objective means for optimizing available choices, a goodness-of-fit metric, $r_{v}$, is defined which measures the RMS variance reduction,

$$
r_{v}^{2}=M_{v}^{-1}\left[\sum_{i}^{M_{v}} d_{v, i}^{2}-\sum_{i}^{M_{v}}\left(\hat{\eta}\left(x_{i}, y_{i}, t_{i}\right)-d_{v, i}\right)^{2}\right],
$$

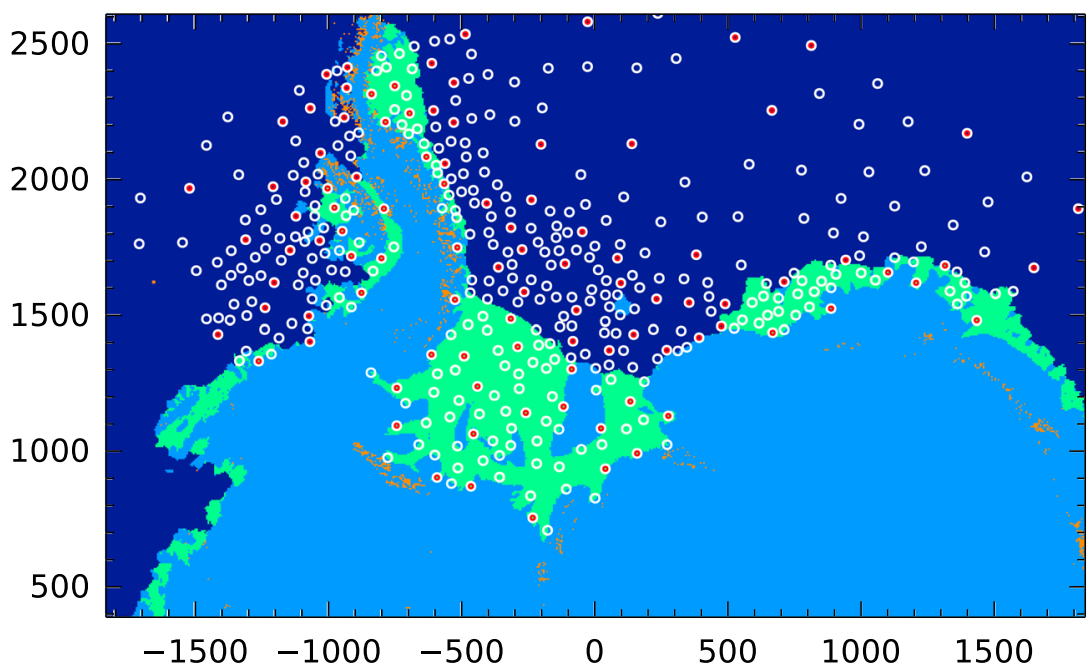

Figure 9. Locations of the first 500 sites from the distribution in Figure 8 (white circles). The surface-type mask of the Rtopo-2 grids indicates ocean (dark blue), ice shelf (green), grounded ice (light blue), and exposed rock (light brown). The crossover sites drawn in red illustrates a coarser subset of 100 sites. The map projection is the same as in previous figures (axis units of kilometers); however, the domain covers the entire extent of the CryoSat- 2 data processed $\left(90^{\circ} \mathrm{W}\right.$ to $0^{\circ} \mathrm{W}$ longitude; poleward of $66^{\circ} \mathrm{S}$ ). 

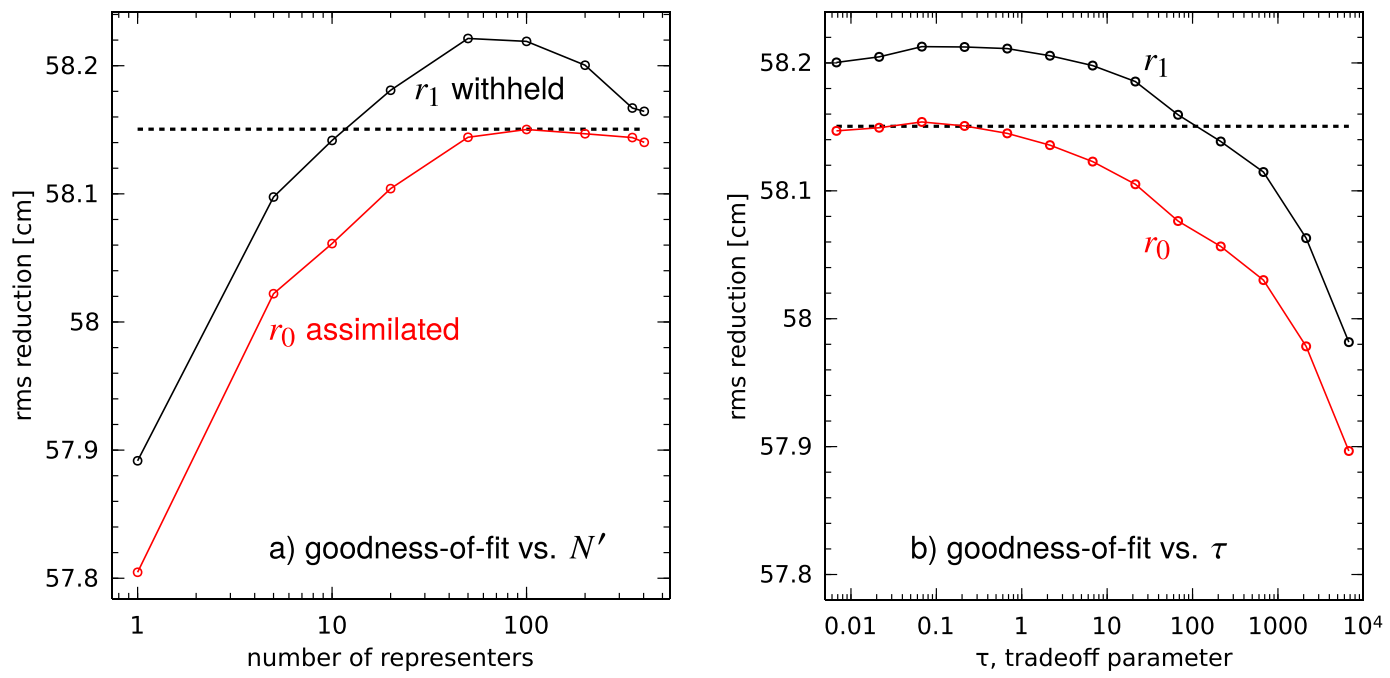

Figure 10. The goodness of fit with respect to the assimilated data $\left(r_{0}\right.$, red $)$ and the withheld data $\left(r_{1}\right.$, black) are shown as a function of $N^{\prime}$ and $\tau$. Note that $r_{1}>r_{0}$ for this particular split between assimilated and withheld data is a coincidence of no particular significance. (a) Holding $\tau=10^{-2}$ constant, $r_{0}$ increases as $N^{\prime}$ is increased (the slight decrease for $N^{\prime}>100$ occurs because $\mathcal{J}$ is computed from a weighted sum of squared data errors, while the $r_{0}$ metric is unweighted), while $r_{1}$ is not improved for $N^{\prime}>50$. The dashed line shows the goodness-of-fit metric computed using the CryoSat-2 IRWLS tide model of Zaron (2018). (b) Holding $N^{\prime}=200$ constant, the values of $r_{0}$ and $r_{1}$ both decrease as $\tau$ is increased for $\tau>0.1$. For $\tau<0.1$, the value of $r_{1}$ drops.

where $\hat{\eta}$ is the tidal prediction computed from the approximate minimizer of equation (25). The subscript $v=0$ indicates the goodness of fit to data which are assimilated $\left\{d_{0, i}\right\}$, and $v=1$ indicates the goodness of fit to data withheld for validation $\left\{d_{1, i}\right\}$. In this case, the assimilated and withheld data correspond to $95 \%$

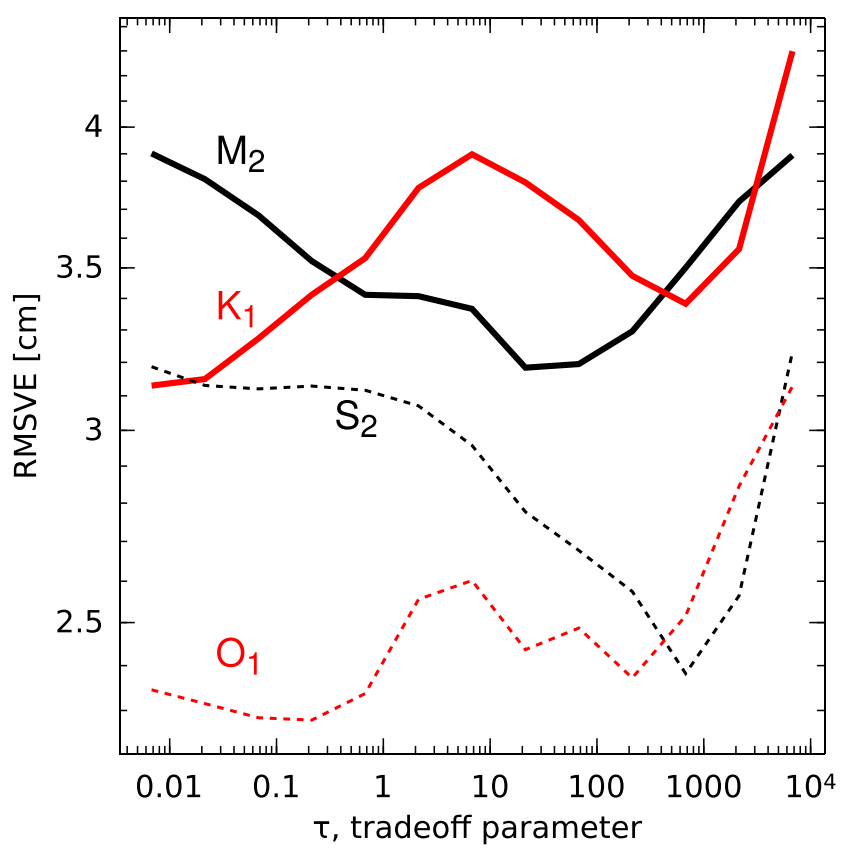

Figure 11. The root-mean-square vector error (RMSVE) of estimated tides is shown as a function of the trade-off parameter, $\tau$, with respect to the subset of Antarctic Tide Gauge Database data described in section 2.3. The RMSVE is remarkably insensitive to the value of $\tau$ within this range, and it is apparently optimized, or nearly so, for $\tau$ between 10 and 1,000, much larger than the optimal value estimated from withheld data (cf., Figure 10). and $5 \%$ subsamples, respectively, of the CryoSat-2 data set. The withheld subsample is created by sampling every twentieth data point along the ground track, resulting an a spatially uniform subsample.

The goodness-of-fit metrics are shown as a function of the parameters, $\left(N^{\prime}, \tau\right)$, in Figure 10. For reference, the dashed line indicates the goodness-of-fit metric for the iteratively reweighted least squares (IRWLS) version of the CryoSat-2-based empirical tide model from Zaron (2018). It is clear that the use of more than about $N^{\prime}=50$ basis functions results in overfitting the assimilated data, as the goodness of fit to the withheld data, $r_{1}$, decreases for $N^{\prime}>50$ (Figure 10a). Taking $N^{\prime}=200$ as given, the trade-off plot indicates that the data are overfit for $\tau<0.1$, approximately (Figure 10b). The conclusions of this validation exercise are based on a single split between assimilated and withheld data; however, other data subsamples indicated similar results (not shown). Note that the goodness-of-fit metric with respect to the assimilated data, $r_{0}$, is not monotonically increasing as $N^{\prime}$ increases or $\tau$ decreases. This occurs because $r_{0}$ is not weighted by the data error, $\sigma_{i}$, as used in equation (25); the weighted goodness-of-fit metric is monotonic (not shown). Also, note that the maximum value of $r_{1}$ displayed in Figure 10a coincides with the IRWLS result (dashed line); this is a coincidence for this particular split of assimilated and withheld data, and the maximum of $r_{1}$ is typically within about $0.1 \mathrm{~cm}$ of this value, depending on the subset of CryoSat-2 data assimilated. The results of using the parameters $\left(N^{\prime}=200, \tau=0.1\right)$ shall be referred to as the nominal case below.

The ATGD provides a completely independent means of validating the data assimilative solutions. The goodness of fit to the ATGD is shown as 

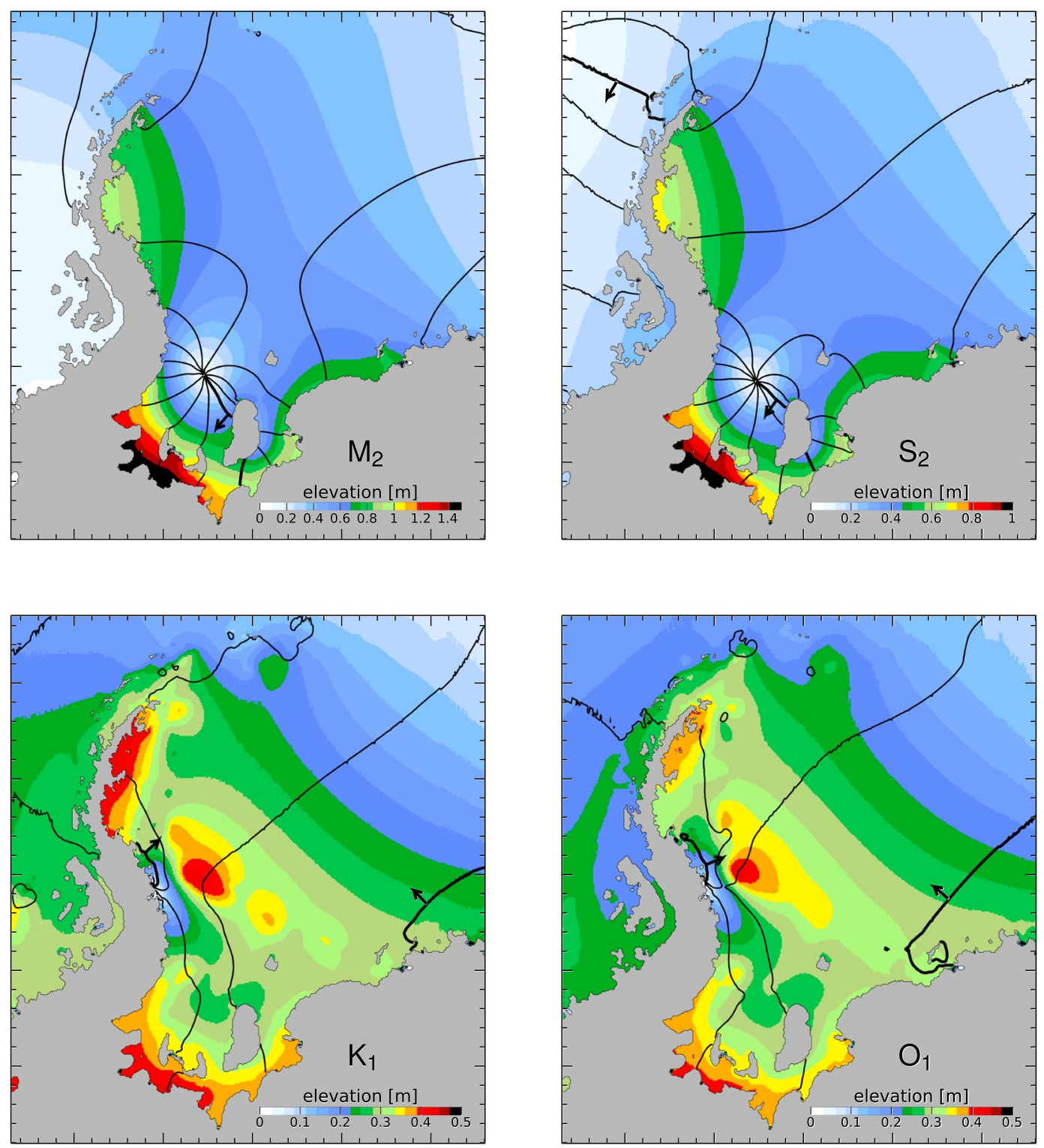

Figure 12. Tide estimates for $N^{\prime}=200$ and $\tau=700$. Color scale and range are the same as in Zaron (2018).

a function of $\tau$ in Figure 11. These data suggest that the $\mathrm{M}_{2}$ and $\mathrm{S}_{2}$ tidal estimates are optimized for $\tau=20$ and $\tau=700$, respectively, while agreement with $\mathrm{K}_{1}$ is optimal for $\tau<0.01$. The metric for $\mathrm{O}_{1}$ is variable, but shows local minima near $\tau=0.2$ and $\tau=200$. The high-quality subset of the ATGD used here contains only 17 sites, so this comparison has hardly the statistical significance compared with the comparison against withheld CryoSat-2 data, but it is interesting that the error with respect to the ATGD is rather insensitive to the choice of $\tau$. The value $\tau=700$ formally underfits the CryoSat- 2 data according to Figure 10, but it results in a reasonable compromise among the errors at the ATGD sites. The results of using the parameters $\left(N^{\prime}=200, \tau=700\right)$ shall be referred to as the underfit case below.

Quantitative error statistics with respect to the ATGD are summarized in Table 1. Errors for the TPXO9.1 model and the CryoSat-2-derived IRWLS model of Zaron (2018) are provided for comparison in the left and right columns, respectively. The Prior Model refers to the nonassimilating model calibrated in section 3.3. Compared to TPXO9.1 and the nonassimilative Prior Model, the present data-assimilative models agree better with the ATGD at every frequency except $\mathrm{K}_{1}$. Agreement with the ATGD data is slightly worse than the IRWLS model of Zaron (2018). 

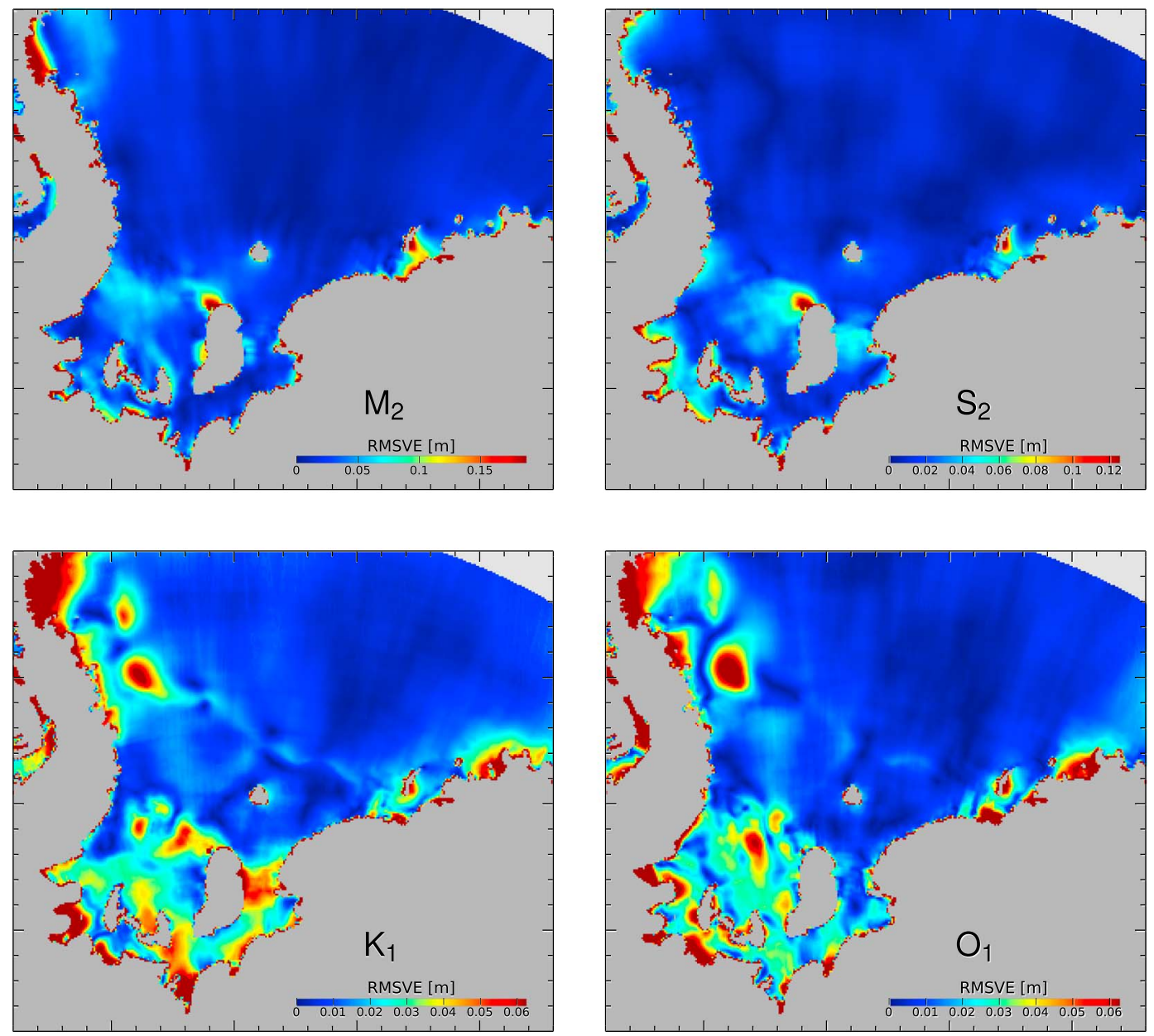

Figure 13. Difference fields (root-mean-square vector error, RMSVE) of the solutions shown in Figure 12 compared with the IRWLS solutions of Zaron (2018). Range of RMSVE is $1 / 8$ the range displayed in Figure 12. Note that the domain shown in this figure does not cover the entire model domain since the models in Zaron (2018) only extend to $66^{\circ} \mathrm{S}$. IRWLS $=$ iteratively reweighted least squares.

The cotidal charts for the underfit solution, mentioned above, are shown in Figure 12. As expected, the tidal fields are grossly similar to previous estimates (Padman et al., 2008; Zaron, 2018), but there are differences in detail. Figure 13 displays difference fields (RMSV difference) with respect to the IRWLS solution of Zaron (2018). Compared to the IRWLS solution, the present estimate of $M_{2}$ is slightly smaller approaching the back of the LIS, and the amplitude varies more gradually along the southern grounding line of the Ronne Ice Shelf. The phase propagation near the FRIS seaward edge is also perturbed, particularly to the northwest of Berkner Island. Similar remarks apply to $\mathrm{S}_{2}$, except that its amplitude is slightly larger than the IRWLS solution under the LIS. Larger relative differences are evident for the $\mathrm{K}_{1}$ and $\mathrm{O}_{1}$ tides, which are increased along most of the eastern side of the Antarctic Peninsula. The peak amplitude at the continental shelf edge is decreased in extent but increased in amplitude in both of the diurnal tides relative to the IRWLS solution. Many smaller-scale differences between the present fields and previous works are evident in the diurnal tides throughout the FRIS and along the east coast of the Weddell Sea. There is slight zonal waviness in the IRWLS fields in the deep ocean (not visible in the present plots) related to the CryoSat-2 orbit, which is completely eliminated in the present solutions.

The adjustments to the bottom topography inferred in the underfit case are shown in Figure 14. This is the correction to the bottom topography or under-ice water column thickness which brings the tidal elevation in to better agreement with the CryoSat-2 observations. A widespread decrease in the depth of the continental shelf in the Weddell Sea is indicated, typically about $10 \%$ of the depth. Larger changes are localized to smaller regions. For example, the depth under the seaward edge of the LIS (near $-700 \mathrm{~km}, 2,300 \mathrm{~km}$ ) is increased by 

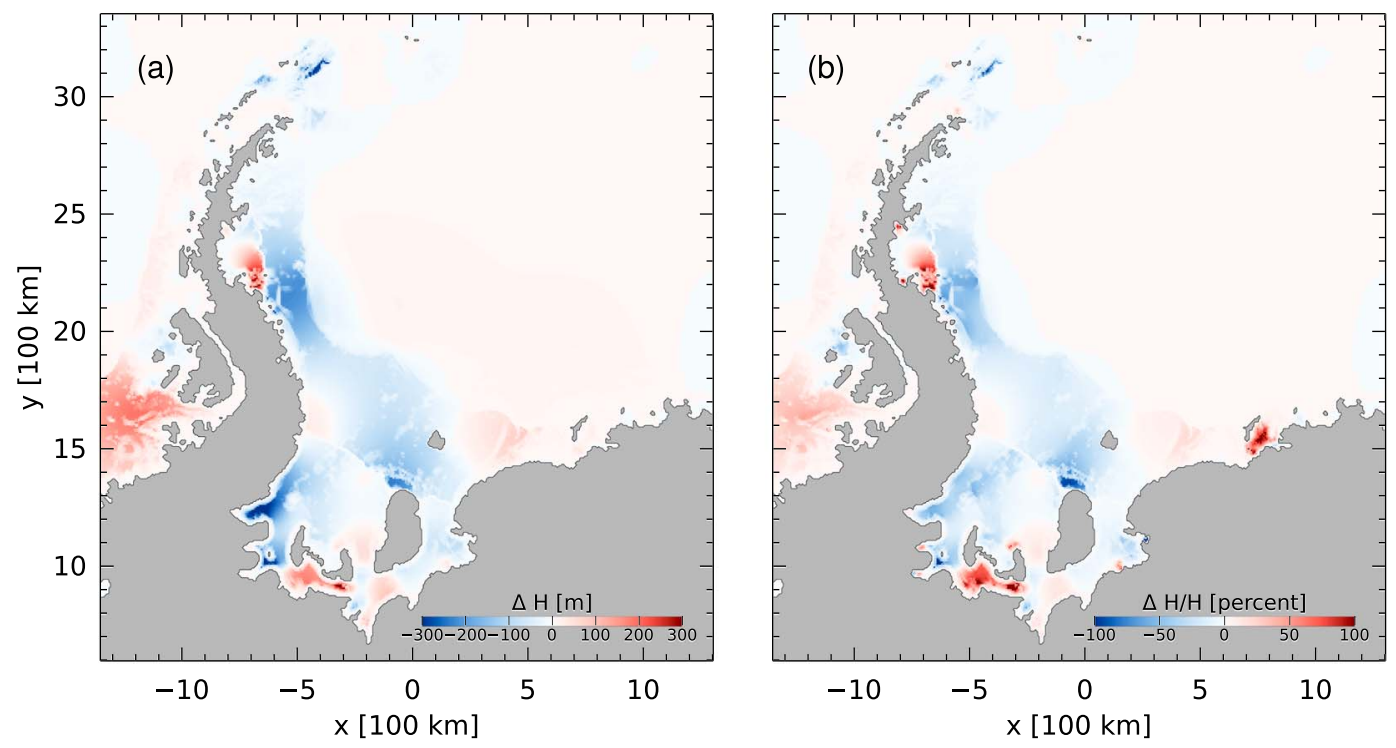

Figure 14. Estimated water column thickness adjustments. (a) Change in water column thickness, $\Delta H$, in units of meters, corresponding to the "underfit" solutions in Figure 12. (b) Fractional change in water column thickness, $\Delta H / \bar{H}$. A widespread of reduction in the depth on the continental shelf around the western and southern Weddell Sea is apparent, which is contrasted with more localized increases in water depth and water column thickness at the LIS and along the back of the FRIS.

more than 50\%, and large increases also occur along the south of the FRIS (-500 km, 1,000 km) and along the east coast $(800 \mathrm{~km}, 1,500 \mathrm{~km})$. There is a substantial decrease in thickness indicated under the western Ronne Ice Shelf ( $-700 \mathrm{~km}, 1,200 \mathrm{~km})$.

The corrections are sensitive to the form assumed for $C_{H}$ and the value of the tradeoff parameter, $\tau$. For $\tau=0.1$, for example, the $\Delta H$ field contains unrealistic small-scale structure (not shown). Direct evaluation of the $\mathcal{J}$ objective function in the vicinity of the $\Delta H$ field obtained with $\tau=0.1$ shows that it is nonquadratic and the tangent linear approximation is not useful for optimizing $\mathcal{J}$. In contrast, the magnitude and spatial structure of $\Delta H$ for $\tau=700$ is more compatible with the dynamics described by the tangent linear system.

It is difficult to assess the realism or accuracy of the water column thickness adjustments, which are corrections to $\bar{H}$ provided by RTopo-2 (Schaffer et al., 2016; Schaffer \& Timmermann, 2016). The reduction in water column thickness under the western Ronne Ice Shelf $(-700 \mathrm{~km}, 1,200 \mathrm{~km})$ appears to be contradicted by evidence for known errors of opposite sign in this region (Johnson \& Smith, 1997; Padman et al., 2018; Smith \& Doake, 1994), while the changes on the continental shelf ( $-600 \mathrm{~km}, 2,200 \mathrm{~km})$ appear to be plausible based on depths inferred from iceburg groundings (Luckman et al., 2010).

In the absence of more in situ observations for validation, the corrected water column thickness, $\bar{H}+\Delta H$, is used to compute predictions for the full suite of tides, $\mathrm{M}_{2}, \mathrm{~S}_{2}, \mathrm{~K}_{1}, \mathrm{O}_{1}$, and $\mathrm{K}_{2}, \mathrm{~N}_{2}, \mathrm{P}_{1}$, and $\mathrm{Q}_{1}$. The latter four tides are generally smaller than the $\mathrm{M}_{2}, \mathrm{~S}_{2}, \mathrm{~K}_{1}$, and $\mathrm{O}_{1}$ tides, but together their instantaneous sum can be as large as $0.5 \mathrm{~m}$ in parts of the FRIS. These four smaller tides were not included in the data assimilation, described above, so the performance of the model for these frequencies with corrected water column thickness ought to provide an independent assessment of its realism. To test this idea, the increment of CryoSat-2 variance reduction associated with the sum of the $\mathrm{K}_{2}, \mathrm{~N}_{2}, \mathrm{P}_{1}$, and $\mathrm{Q}_{1}$ tidal predictions was computed (Figure 15; note that the larger tides are omitted because of the much larger positive increment of variance reduction associated with them). The figure shows the quantity, $\Delta_{v}$, defined as,

$$
\Delta_{v}=\left\langle\left(\eta_{i}-\eta(\bar{H})\right)^{2}\right\rangle-\left\langle\left(\eta_{i}-\eta(\bar{H}+\Delta H)\right)^{2}\right\rangle,
$$

where the angle brackets indicate averaging within approximately 7-km $\times 7-\mathrm{km}$ bins of latitude and longitude, $\eta_{i}$ is the observed elevation, and $\eta(H)$ is the predicted tidal elevation. Where this quantity is positive, it indicates that the $\Delta H$-adjusted tide prediction for $\mathrm{K}_{2}, \mathrm{~N}_{2}, \mathrm{P}_{1}$, and $\mathrm{Q}_{1}$ is better than the nonadjusted tide prediction. The meridional stripes in the pattern of variance reduction in Figure 15 are the result of geographic correlations of the tidal phase sampled by CryoSat-2 (Zaron, 2018). The area average variance reduction 


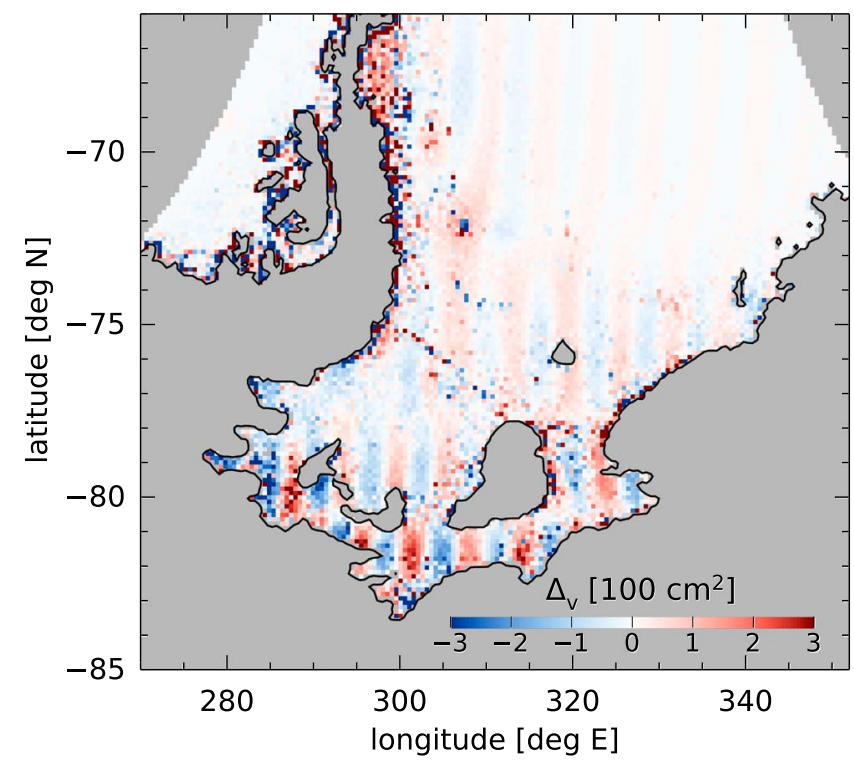

Figure 15. Increment in variance reduction, $\Delta_{v}$, for $\mathrm{K}_{2}, \mathrm{~N}_{2}, \mathrm{P}_{1}$, and $\mathrm{Q}_{1}$ tides computed from $\bar{H}$ versus $\bar{H}+\Delta H$. The variance reduction (units of square centimeters) is computed by averaging the CryoSat-2 statistics within approximately 7-km $\times 7-\mathrm{km}$ squares, each containing about 200 measurements at $1 \mathrm{~Hz}$. Positive values (red) indicate where the adjusted water column thickness leads to improvements in the prediction of these smaller tides. Although the spatial average of $\Delta_{v}$ is positive, about $5 \mathrm{~cm}^{2}$, this value is the sum of large contributions of both signs which largely cancel; the incremental increase in variance explained by these tides is too small to lend confidence to the $\Delta H$ field estimated (Figure 14). (Note the geographic distortion of this map, which is based on a latitude-longitude grid; gray areas in the northeast and northwest corners are regions not covered by the computational domain.)

is sensitive to detailed criteria for rejecting noisy or potentially anomalous data, with values in the range $\pm 5 \mathrm{~cm}^{2}$ possible. Tide predictions at the LIS are improved, but a widespread positive impact of the adjusted water column thickness is not apparent.

\section{Discussion and Summary}

The aim of this work was to produce more accurate maps of seafloor topography and under-ice water column thickness useful for studies of Weddell Sea ice shelf dynamics or, more broadly, ocean circulation (Orsi et al., 1999) and sea level rise (Mengel et al., 2016). The technical approach involved linearization of the tidal dynamics and the computation of adjoint sensitivity with respect to variations in the water column thickness, $H$, and, secondarily, parameters in submodels for tidal dissipation, $C_{d}, C_{v}$, and $C_{a}$. The linearized system and its adjoint were then used to assimilate CryoSat-2 altimetry in order to infer both the tidal fields and water column thickness. While this approach is a technical innovation with respect to previous efforts, it was not capable of significantly improving the initial estimate of water column thickness provided by Rtopo-2. A wide range of $\Delta H$ increments is parameterized by both the trade-off parameter, $\tau$, and the number of representer basis functions, $N^{\prime}$; however, the tidal elevation at independent ATGD data sites is remarkably insensitive to these changes (Figure 11). At this level of precision, the water column thickness is not uniquely determined by the available measurements.

The validation against independent ATGD data led to a larger estimate for $\tau$ than was obtained by validation against withheld CryoSat-2 data. This likely reflects the presence of spatially correlated nontidal signals (not instrumental error) in the CryoSat-2 data. Such a correlation was not modeled in the data error term in equation (25); therefore, correlations between the assimilated and withheld CryoSat-2 data probably bias the selection of $\tau$ toward overfitting. The relatively small, but independent, ATGD data set is thus extremely valuable for validation.

The proposed drag parameterizations yielded substantial improvements in the accuracy of the tide model (Figure 2). Presumably the drag parameterization should be equally applicable in other locations where there is coupling between the subinertial tides and topography. It is unclear if the energy loss associated with these terms is localized dissipation (as is the case with the conventional interfacial drag) or 
loss of phase-locking due to interactions with nontidal flow. Their positive impact suggests that the distinction between tidal dissipation and nonphase-locked variability at subinertial tidal frequencies ought to be accounted for in energetic analyses of tides. Presumably the dissipation contributes to the thermodynamics and water mass transformations in the Weddell Sea, while the apparent dissipation related to the generation of nonphase-locked tides does not.

Predictions for the $\mathrm{M}_{2}, \mathrm{~S}_{2}, \mathrm{~K}_{1}$, and $\mathrm{O}_{1}$ tides from the present work may be compared with predictions of other models, for eample, TPXO9.1 and CATS8a, by evaluating the variance reduction with respect to the CryoSat-2 observations. This comparison shows that the present model, for $\tau=700$, is unambiguously more accurate than the global TPXO9.1 model, explaining about $370 \mathrm{~cm}^{2}$ more variance than the latter. The variance reduction for the present model is only about $6 \mathrm{~cm}^{2}$ larger than for the CATS8a model. While this difference is statistically significant (it is about 4 times larger than the uncertainty in this quantity, as estimated by bootstrap resampling), it is probably not of practical significance since the present results were obtained by assimilating these same data. We are left with the situation-perhaps unsurprisingly-where the CATS8a and the present model each exhibit slightly better goodness of fit with respect to the data each assimilated, ATGD and CryoSat-2, respectively.

CryoSat-2 was not optimized for tidal studies, and it is challenging to work with because of the high spatial density of its ground tracks and its suboptimal phase sampling of certain tides. The present work has found that the CryoSat-2 data can be used to estimate tides with a precision comparable to that available from other data sources, even if they were not found useful for identifying topography or water column thickness. Improvements may be anticipated from innovations in processing CryoSat-2 waveforms over ice surfaces (Nilsson et al., 2016) and ocean surfaces (Boy et al., 2017; Idzanovic et al., 2018), and a new version of the entire CryoSat-2 geophysical data record is being prepared (Bouffard et al., 2018). Future efforts should aim to utilize these data more widely for mapping tides in the polar oceans.

\section{Acknowledgments}

Two reviewers provided useful feedback on this manuscript, and their efforts are greatly appreciated. Laurie Padman and Richard Ray are gratefully acknowledged for discussions regarding ice shelf dynamics and altimeter sampling. The numerical tide model and its associated data assimilation software were based on the Oregon State University Tidal Inversion Software (OTIS, http:// volkov.oce.orst.edu/tides/otis.html), developed and provided by Gary Egbert and Lana Erofeeva; their assistance with the OTIS software is gratefully acknowledged. The CryoSat- 2 data were extracted from the Level-2 Baseline-C Surface Elevation Product, which may be obtained from the Center for Topographic studies of the Ocean and Hydrosphere (CTOH; http://ctoh.legos.obs-mip.fr/products/ alongtrack-data/cryosat2-request-form). This project was supported by NASA award NNX13AH06G.

\section{References}

Allen, J. S. (1975). Coastal trapped waves in a stratified ocean. Journal of Physical Oceanography, 5, 300-325.

Alley, R. B., Clark, P. U., Huybrechts, P., \& Joughin, I. (2005). Ice-sheet and sea-level changes. Science, 310(5747), 456-460.

Andrews, B., \& Hopper, C. (2011). The Ricci flow in Riemannian geometry, 2011 in Lecture Notes in Mathematics. New York: Springer.

Arndt, J. E., Schenke, H. W., Jakobsson, M., Nitsche, F. O., Buys, G., Goleby, B., et al. (2013). The International Bathymetric Chart of the Southern Ocean (IBCSO) Version 1.0-A new bathymetric compilation covering circum-Antarctic waters. Geophysical Research Letters, 40, 3111-3117.

Bennett, A. F. (1992). Inverse methods in physical oceanography (1st ed., pp. 346). New York: Cambridge University Press.

Bennett, A. F. (2002). Inverse modeling of the ocean and atmosphere (pp. 234). New York: Cambridge University Press.

Bennett, A., \& Budgell, W. (1987). Ocean data assimilation and the Kalman filter: Spatial regularity. Journal of Physical Oceanography, 17, $1583-1601$.

Bouffard, J., Naeije, M., Banks, C. J., Calafat, F. M., Cipollini, P., Snaith, H. M., et al. (2018). CryoSat ocean product quality status and future evolution. Advance Spares Research, 62(6), 1549-1563.

Bouzinac, C. (2012). CryoSat-2 product handbook (pp. 150). London, UK: ESRIN-ESA and Mullard Space Science Laboratory, University College London.

Boy, F., Desjonquères, J.-D., Picot, N., Moreau, T., \& Raynal, M. (2017). CryoSat-2 SAR-mode over oceans: Processing methods, global assessment, and benefits. IEEE Transactions on Geoscience and Remote Sensing, 55(1), 148-158.

Brenner, A. C., DiMarzio, J. P., \& Zwally, H. J. (2007). Precision and accuracy of satellite radar and laser altimeter data over continental ice sheets. IEEE Transactions on Geoscience and Remote Sensing, 45(2), 321-331.

Carrère, L., \& Lyard, F. (2003). Modelling the barotropic response of the global ocean to atmospheric wind and pressure forcing-Comparisons with observations. Geophysical Research Letters, 30(6), 1275. https://doi.org/10.1029/2002GL016473

Carrère, L., Lyard, F., Cancet, M., Guillot, A., Picot, N., \& Dupay, S. (2015). FES 2014, a new tidal model on the global ocean with enhanced accuracy in shallow seas and in the Arctic region, presented at the 2015. VA, USA: Ocean Surface Topography Science Team Meeting Reston.

Cressie, N., \& Wilke, C. K. (2011). Statistics for spatio-temporal data (pp. 588). Hoboken, NJ: John Wiley.

Dronkers, J. J. (1964). Tidal computations in rivers and coastal waters (pp. 518). Amsterdam: North Holland Publishing Co.

Egbert, G. D., Bennett, A. F., \& Foreman, M. (1994). TOPEX/POSEIDON tides estimated using a global inverse model. Journal of Geophysical Research, 99, 24,821-24,852.

Egbert, G. D., \& Erofeeva, S. Y. (2002). Efficient inverse modeling of barotropic ocean tides. Journal of Atmospheric and Oceanic Technology, 19, 183-204.

Egbert, G. D., \& Erofeeva, S. Y. (2018). OSU Tidal Inversion Software (OTIS) global tide model version TPXO9.1. http://volkov.oce.orst.edu/ tides/global.html accessed 2018-09-12

Errico, R. M. (1997). What is an adjoint model? Bulletin of the American Meteorological Society, 78(11), 2577-2591.

Fretwell, P., Pritchard, H. D., Vaughan, D. G., Bamber, J. L., Barrand, N. E., Bell, R., et al. (2013). Bedmap2: Improved ice bed, surface and thickness datasets for Antarctica. The Cryosphere, 7(1), 375-393.

Fricker, H. A., \& Padman, L. (2002). Tides on Filchner-Ronne ice shelf from ERS radar altimetry. Geophysical Research Letters, 29(12), 1622. https://doi.org/10.1029/2001GL014175

Gratton, Y., \& LeBlond, P. H. (1986). Vorticity waves over strong topography. Journal of Physical Oceanography, 16, $151-166$. 
Griggs, J. A., \& Bamber, J. L. (2011). Antarctic ice-shelf thickness from satellite radar altimetry. Journal of Glaciology, 57(203), 485-498. Hinze, J. O. (1975). Turbulence (2nd ed.), (pp. 790). New York: McGraw-Hill Publishing.

Idzanovic, M., Ophaug, V., \& Andersen, O. B. (2018). Coastal sea level from CryoSat-2 SARIn altimetry in Norway. Advances in Space Research, 62(6), 1344-1357.

Jakobsson, M., Armstrong, A., Calder, B., Huff, L., Mayer, L., \& Ward, L. (2005). On the use of historical bathymetric data to determine changes in bathymetry: An analysis of errors and application to Great Bay Estuary, NH. International Review of Hydrobiology, 6(3), 25-41.

Jakobsson, M., Calder, B., \& Mayer, L. (2002). On the effect of random errors in gridded bathymetric compilations. Journal of Geophysical Research, 107(B12), 2350.

Johnson, M. R., \& Smith, A. M. (1997). Seabed topography under the southern and western Ronne Ice Shelf, derived from seismic surveys. Ant Science, 9(2), 201-208

King, M. A., Padman, L., Nicholls, K., Clarke, P. J., Gudmundsson, G. H., Kulessa, B., et al. (2011). Ocean tides in the Weddell Sea: New observations on the Filchner-Ronne and Larsen C ice shelves and model validation. Journal of Geophysical Research, 116, C06006. https:// doi:10.1029/2011JC006949

Lavelle, J. W., \& Mofjeld, H. O. (1983). Effects of time-varying viscosity on oscillatory turbulent channel flow. Journal of Geophysical Research, 88(C12), 7607-7616.

Lefevre, F., LeProvost, C., \& Lyard, F. H. (2000). How can we improve a global ocean tide model at a regional scale? A test on the Yellow Sea and the East China Sea. Journal of Geophysical Research, 105(C4), 8707-8725.

Lu, P., Li, Z., Cheng, B., \& Lepparanta, M. (2011). A parameterization of the ice-ocean drag coefficient. Journal of Geophysical Research, 116, C07019. https://doi.org/10.1029/2010JC006878

Luckman, A., Padman, L., \& Jansen, D. (2010). Persistent iceberg groundings in the western Weddell Sea. Remote Sensing of Environment, 114, 385-391.

Lythe, M., Vaughan, D. G., \& The BEDMAP Consortium (2001). BEDMAP: A new ice thickness and subglacial topographic model of Antarctica. Geophysical Research Letters, 106, 11,335-11,352.

MacAyeal, D. R. (1984). Numerical simulations of the Ross Sea tides. Geophysical Research Letters, 96(C11), 20,671-20,677.

Makinson, K. (2002). Modeling tidal current profiles and vertical mixing beneath Filchner-Ronne Ice Shelf, Antarctica. Journal of Physical Oceanography, 32, 202-215.

Makinson, K., Schröder, M., \& Osterhus, S. (2006). Effect of critical latitude and seasonal stratification on tidal current profiles along Ronne Ice Front, Antarctica. Journal of Geophysical Research, 111, C03022. https://doi.org/10.1175/1520-0485(2002)032<0202:?MTCPAV>2.0

Marks, K., \& Smith, W. H. (2008). An uncertainty model for deep ocean single beam and multibeam echo sounder data. Marine Geophysical Research, 29(4), 239-250.

Marks, K. M., \& Smith, W. H. (2012). Radially symmetric coherence between satellite gravity and multibeam bathymetry grids. Marine Geophysical Research, 33(3), 223-227.

Marks, K., Smith, W., \& Sandwell, D. (2010). Evolution of errors in the altimetric bathymetry model used by Google Earth and GEBCO. Marine Geophysical Research, 31, 223-238.

McMillan, M., Corr, H., Shepherd, A., Ridout, A., Laxon, S., \& Cullen, R. (2013). Three-dimensional mapping by CryoSat-2 of subglacial lake volume changes. Geophysical Research Letters, 40, 4321-4327. https://doi:10.1002/grl.50689

McMillan, M., Shepherd, A., Muir, A., Gaudelli, J., Hogg, A. E., \& Cullen, R. (2018). Assessment of CryoSat-2 interferometric and non-interferometric SAR altimetry over ice sheets. Advance Spares Research, 62(6), 1281-1291.

Mengel, M., Levermann, A., Frieler, K., Robinson, A., Marzeion, B., \& Winkelmann, R. (2016). Future sea level rise constrained by observations and long-term commitment. Proceedings of the National Academy of Sciences, 113(10), 2597-2602.

Middleton, J. H., Foster, T. D., \& Foldvik, A. (1987). Diurnal shelf waves in the southern Weddell Sea. Journal of Physical Oceanography, 17, 784-791.

Mirouze, I., \& Weaver, A. (2012). On the diffusion equation and its application to isotropic and anisotropic correlation modelling in variational assimilation. Quarterly Journal of the Royal Meteorological Society, 139, 242-260.

Mueller, R. D. (2014). The effects of thermodynamic parameterizations, ice-shelf geometry, and tides on modeled basal melting of Weddell Sea ice shelves (PhD thesis), Oregon, USA.

Nilsson, J., Gardner, A., Sørensen Sandberg, L., \& Forsberg, R. (2016). Improved retrieval of land ice topography from CryoSat-2, data and its impact for volume-change estimation of the Greenland ice sheet. The Cryosphere, 10(6), 2953-2969.

Orsi, A., Johnson, G., \& Bullister, J. (1999). Circulation, mixing, and production of Antarctic bottom water. Progress in Oceanography, 43(1), 55-109.

Padman, L., Erofeeva, S. Y., \& Fricker, H. A. (2008). Improving Antarctic tide models by assimilation of ICESat laser altimetry over ice shelves. Geophysical Research Letters, 35, L22504. https://doi:10.1029/2008GL035592

Padman, L., \& Fricker, H. A. (2005). Tides on the Ross ice shelf observed with ICESat. Geophysical Research Letters, 32, L14503. https:// doi:10.1029/2005GL023214

Padman, L., Fricker, H. A., Coleman, R., Howard, S., \& Erofeeva, S. (2002). A new tidal model for the Antactic ice shelves and seas. Annals of Glaciology, 34, 247-254.

Padman, L., Howard, S. L., Orsi, A. H., \& Muench, R. D. (2009). Tides of the northwestern Ross Sea and their impact on dense outflows of Antarctic bottom water. Deep Sea Research, II(59), 818-834.

Padman, L., \& King, M. A. (2017). ESR Antarctic tide gauge database. accessed 2017-04-20.

Padman, L., \& Kottmeier, C. (2000). High-frequency ice motion and divergence in the Weddell Sea. Journal of Geophysical Research, 105(19), 3379-3400.

Padman, L., Siegfried, M. R., \& Fricker, H. A. (2018). Ocean tide influences on the Antarctic and Greenland ice sheets. Reviews of Geophysics, 56, 142-184.

Perlin, A., Moum, J. N., Klymak, J. M., Levine, M. D., Boyd, T., \& Kosro, P. M. (2005). A modified law-of-the-wall applied to oceanic bottom boundary layers. Journal of Geophysical Research, 110, C10S10. https://doi:10.1029/2004JC002310

Ray, R. D. (2008). A preliminary tidal analysis of ICESat laser altimetry: Southern Ross ice shelf. Geophysical Research Letters, 35 , L02505. https://doi:10.1029/2007GL032125

Rignot, E., Mouginot, J., \& Scheuchl, B. (2011). Antarctic grounding line mapping from differential satellite radar interferometry. Geophysical Research Letters, 38, L10504. https://doi:10.1029/2011GL047109

Robertson, R. (2001a). Internal tides and baroclinicity in the southern Weddell Sea: Part II: Effects of the critical latitude and stratification Journal of Geophysical Research, 106, 27,017-27,034.

Robertson, R. (2001b). Internal tides and baroclinicity in the southern Weddell Sea: Part I: Model description, and comparison of model results to observations. Journal of Geophysical Research, 106, 27,001-27,016. 
Robertson, R. (2005). Baroclinic and barotropic tides in the Weddell Sea. Antarctic Science, 17(3), 461-474.

Robertson, R., Padman, L., \& Egbert, G. D. (1998). Tides in the Weddell Sea, Ocean, ice, and atmosphere: Interactions at the Antarctic Continental, Margin, Antarctic Research Series (Vol. 75, pp. 341-369). Washington, DC: American Geophysical Union.

Robinson, N. J., Stevens, C. L., \& McPhee, M. G. (2017). Observations of amplified roughness from crystal accretion in the sub-ice ocean boundary layer. Geophysical Research Letters, 44, 1814-1822. https://doi.org/10.1002/2016GL071491

Rosier, S. H. R., Green, J. A. M., Scourse, J. D., \& Winkerlmann, R. (2014). Modeling Antarctic tides in response to ice shelf thinning and retreat. Journal of Geophysical Research: Oceans, 119, 87-97. https://doi.org/10.1002/2013JC009240

Schaffer, J., \& Timmermann, R. (2016). Greenland and Antarctic ice sheet topography, cavity geometry, and global bathymetry (RTopo-2), links to NetCDF files, doi:10.1594/PANGAEA.856844, supplement to: Schaffer, Janin; Timmermann, Ralph; Arndt, Jan Erik; Kristensen, Steen Savstrup; Mayer, Christoph; Morlighem, Mathieu; Steinhage, Daniel (2016): A global, high-resolution data set of ice sheet topography, cavity geometry, and ocean bathymetry. Earth System Science Data, 8(2), 543-557. https://doi:10.5194/essd-8-543-2016

Schaffer, J., Timmermann, R., Arndt, J. E., Mayer, C., Morlighem, M., \& Steinhage, D. (2016). A global, high-resolution data set of ice sheet topography, cavity geometry, and ocean bathymetry. Earth System Science Data, 8, 543-557.

Shaw, W. J., Stanton, T. P., McPhee, M. G., \& Kikushi, T. (2008). Estimates of surface roughness length in heterogeneous under-ice boundary layers. Journal of Geophysical Research, 113, C08030. https://doi:10.1029/2007JC004550

Skardhamar, J., Skagseth, O., \& Albretsen, J. (2015). Diurnal tides on the Barents Sea continental slope. Deep Sea Research, 97, 40-51.

Smith, W. H. (1993). On the accuracy of digital bathymetric data. Journal of Geophysical Research, 98(B6), 9591-9603.

Smith, A. M., \& Doake, C. S. M. (1994). Sea-bed depths at the mouth of Rutford Ice Stream Antarctica. Annals of Glaciology, 20(1), 353-356.

Smith, W. H., \& Sandwell, D. T. (1997). Global sea floor topography from satellite altimetry and ship depth soundings. Science, 277, 1956-1962.

Smithson, M. J., Robinson, A. V., \& Flather, R. A. (1996). Ocean tides under the Filchner-Ronne Ice Shelf, Antactica. Annals of Glaciology, 23, 217-225.

Snyder, R. L., Sidjabat, M., \& Filloux, J. H. (1979). A study of tides, setup and bottom friction in a shallow semi-enclosed basin. Part II: Tidal model and comparison with data. Journal of Physical Oceanography, 9, 170-188.

Stammer, D., Ray, R. D., Andersen, O. B., Arbic, B. K., Bosch, W., Carrère, L., et al. (2014). Accuracy assessment of global barotropic ocean tide models. Reviews of Geophysics, 52, 243-282.

Stanton, T. P., Shaw, W. J., Truffer, M., Corr, H., Peters, L. E., Riverman, K. L., et al. (2013). Channelized ice melting in the ocean boundary layer beneath Pine Island Glacier, Antarctica. Science, 341, 1236-1239.

Wahba, G. (1990). Spline models for observational data. Philadelphia: SIAM publications.

Weatherall, P., Marks, K. M., Jakobsson, M., Schmitt, T., Tani, S., Arndt, J. E., et al. (2015). A new digital bathymetric model of the world's oceans. Earth and Space Science, 2, 331-345.

Webb, E., \& Hall, A. (2016). Geophysical corrections in Level 2 CryoSat data products (Tech. Rep. ESRIN-EOP-GMQ/IDEAS+, version 5.1, reference IDEAS-VEG-IPF-MEM-1288): European Space Agency.

Wessel, P., \& Chandler, M. (2011). The spatial and temporal distribution of marine geophysical surveys. Acta Geophysica, 59, 55-71.

Wiese, D. N., Killett, B., Watkins, M. M., \& Yuan, D.-N. (2016). Antarctic tides from GRACE satellite accelerations. Journal of Geophysical Research: Oceans, 121, 2874-2886. https://doi.org/10.1002/2015JC011488

Xing, J., \& Davies, A. M. (1995). The influence of mixing length formulation and stratification upon tidal currents in shallow seas. Estuarine, Coastal and Shelf Science, 42, 417-456.

Yen, B. C. (1986). Hydraulic resistance in open channel flow. In B. C. Yen (Ed.), Channel flow resistance: Centennial of Manning's formula (pp. 1-135, 453 pp.) Highland Ranch, CO: Water Resources Publications.

Zaron, E. D. (2016). On the observability of bottom topography from measurements of sea surface height. Ocean Mod, $102,55-63$.

Zaron, E. D. (2017). Topographic and frictional controls on tides in the Sea of Okhotsk. Ocean Modeling, 117C, 1-11.

Zaron, E. D. (2018). Ocean and ice shelf tides from CryoSat-2 altimetry. Journal of Physical Oceanography, 48, 975-993.

Zaron, E. D., \& Egbert, G. D. (2006). Estimating open-ocean barotropic tidal dissipation: The Hawaiian Ridge. Journal of Physical Oceanography, 36, 1019-1035.

Zauderer, E. (1983). Partial differential equations of applied mathematics (pp. 779). New York: John Wiley, Wiley-Interscience. 